\title{
Pitch Structure, But Not Selective Attention, Affects Accent Weightings in Metrical Grouping
}

\author{
Jon B. Prince \\ Murdoch University
}

\begin{abstract}
Among other cues, pitch and temporal accents contribute to grouping in musical sequences. However, exactly how they combine remains unclear, possibly because of the role of structural organization. In 3 experiments, participants rated the perceived metrical grouping of sequences that either adhered to the rules of tonal Western musical pitch structure (musical key) or did not (atonal). The tonal status of sequences did not provide any grouping cues and was irrelevant to the task. Experiment 1 established equally strong levels of pitch leap accents and duration accents in baseline conditions, which were then recombined in subsequent experiments. Neither accent type was stronger or weaker for tonal and atonal contexts. In Experiment 2, pitch leap accents dominated over duration accents, but the extent of this advantage was greater when sequences were tonal. Experiment 3 ruled out an attentional origin of this effect by replicating this finding while explicitly manipulating attention to pitch or duration accents between participant groups. Overall, the presence of tonal pitch structure made the dimension of pitch more salient at the expense of time. These findings support a dimensional salience framework in which the presence of organizational structure prioritizes the processing of the more structured dimension regardless of task relevance, independent from psychophysical difficulty, and impervious to attentional allocation.
\end{abstract}

Keywords: pitch, time, music, dimensional processing

Supplemental materials: http://dx.doi.org/10.1037/a0037730.supp

The seminal Gestalt approach to the study of perception provided principles that describe how external stimuli are organized into coherent percepts. Although the primary application of these rules are in visual perception (Wagemans et al., 2012), they have also been applied to auditory processing, particularly in the context of auditory stream segregation (Alain \& Arnott, 2000; Bregman, 1990). Gestalt principles are also relevant to the larger concept of auditory objects (Kubovy \& Van Valkenburg, 2001; Snyder \& Alain, 2007), based on extracting regularities from the environment (Winkler, Denham, \& Nelken, 2009). Music provides an ideal domain for investigating grouping in auditory sequences, because it is central to the perceptual organization of individual musical notes (Jones, 1976), musical phrases (Deutsch \& Feroe, 1981; Sloboda \& Gregory, 1980), separating instruments (Handel, 1995), and large-scale structure (Clarke \& Krumhansl, 1990; Lerdahl \& Jackendoff, 1983).

Musical accents, or points of stress, make individual events stand out from the surrounding notes. They are the basis of grouping in music (Deutsch, 1999; Thomassen, 1982; van Noorden, 1975), and occur in a number of dimensions, or information sources. A pitch leap (a large-frequency change between adjacent notes), or a change in pitch contour (switching between frequency increases/decreases in a melody), highlights the note

This article was published Online First August 11, 2014.

Correspondence concerning this article should be addressed to Jon B. Prince, Department of Psychology and Exercise Science, Murdoch University, 90 South Street, Murdoch, WA 6150, Australia. E-mail: j.prince@murdoch.edu.au following the change, and is fundamental to melodic perception (Dowling, 1978; Schmuckler, 2009). There are numerous other accent types, such as variations in duration (Cooper \& Meyer, 1960; Vos, 1977), a silent gap between notes (Jones \& Pfordresher, 1997; Preusser, Garner, \& Gottwald, 1970), a change in loudness (Repp, 1995; Gürkan Tekman, 2002), or a timbral change (Cusack \& Roberts, 2000).

An emergent property of accents in musical sequences is meter, the periodic oscillation between strong and weak points in time more commonly known as the beat or pulse of a given musical passage (Lerdahl \& Jackendoff, 1983). The placement of accents determines the metric framework (Hannon, Snyder, Eerola, \& Krumhansl, 2004; Parncutt, 1994; Povel \& Essens, 1985), but meter is an abstract and hierarchical structure that is extracted from the accent patterns comprising the musical surface features (London, 2004). Many different accent sequences can nonetheless invoke the same metric framework (cf. Povel \& Essens, 1985). Similarly, the exact same accent pattern can with conscious effort be interpreted in different metric frameworks (Repp, 2007). In Western music, musical meter largely uses either binary (strongweak) or ternary (strong-weak-weak) groupings, although both types can be combined when nested hierarchically (London, 1995). Despite its abstract nature, meter is a fundamental component of music (Palmer \& Krumhansl, 1990), which is observable from infancy (Hannon \& Johnson, 2005; Zentner \& Eerola, 2010), arises spontaneously (Ladinig, Honing, Haden, \& Winkler, 2009)—even from isochronous sequences of identical notes (Brochard, Abecasis, Potter, Ragot, \& Drake, 2003; Potter, Fenwick, Abecasis, \& Brochard, 2009)—is neurally observable (Snyder \& Large, 2005), 
and dissociable from the processing of rhythm (Geiser, Ziegler, Jancke, \& Meyer, 2009).

Given its centrality to musical behavior, it is hardly surprising that meter influences the perception of musical sequences. Detecting changes to a temporal pattern is easier if it conforms to a regular metrical framework (Grube \& Griffiths, 2009; Hébert \& Cuddy, 2002). Indeed, metric sequences are overall more accurately encoded, processed, and remembered than nonmetric sequences (Keller \& Burnham, 2005; Povel \& Essens, 1985). The benefits of metrical structure extend to production paradigmsstrong beats provide stable reference points for tapping (Repp, Iversen, \& Patel, 2008); conversely, synchronization is more difficult when sequences are only weakly metrical (Patel, Iversen, Chen, \& Repp, 2005). Metrical patterns even aid tapping on weak metric locations (Keller \& Repp, 2005) and in unfamiliar metrical frameworks (Tillmann, Stevens, \& Keller, 2011). The presence of a metrical framework can also create distortions, such that the detection of timing perturbations is superior for strong metric locations, but inferior at weak positions (Repp, 1992). Estimations of event duration are similarly affected-listeners perceive sequences whose metric structures suggest an earlier ending point as longer than identical sequences that suggest a later ending point, giving systematic over-/underestimations consistent with the metric framework (Jones \& Boltz, 1989; Jones, Boltz, \& Klein, 1993). One possible mechanism for these effects is that metric frameworks direct attention toward metrically strong points in time rather than systematic perceptual distortions (Ellis \& Jones, 2010; Repp, 2010). However, there is no benefit for implicit learning of metric patterns in a serial reaction time task (involving online attending), suggesting that the source is not attentional but relevant only for encoding and retrieval (Schultz, Stevens, Keller, \& Tillmann, 2013).

Meter is not the only abstract and hierarchical structure in music. Tonality (or musical key) provides a hierarchical arrangement of the 12 pitch classes per octave, and is central to the perception of music. For one of many examples, tonality affects the detection of mistuned notes in musical sequences (Cohen \& Frankland, 1990; Cohen, Trehub, \& Thorpe, 1989; Cuddy, Cohen, \& Miller, 1979; Marmel, Tillmann, \& Dowling, 2008; Trainor \& Trehub, 1993; Warrier \& Zatorre, 2002). Also, recognition memory is superior for tonal melodies than atonal (no musical key) ones (Bharucha \& Krumhans1, 1983; Dowling, 1991; Freedman, 1999; Schulze, Dowling, \& Tillmann, 2012). The role of tonality in music perception is so strong that it creates a processing cost for less tonally related events (Tillmann, Janata, Birk, \& Bharucha, 2003, 2008) and can mask otherwise noticeable changes in melodies (Trainor \& Trehub, 1992, 1994). Neural evidence has shown specific neural loci and activation patterns for tonality (Fedorenko, McDermott, Norman-Haignere, \& Kanwisher, 2012; Janata et al., 2002; Koelsch, 2005; Marmel, Perrin, \& Tillmann, 2011), and that tonal relations are processed preattentively (Brattico, Näätänen, \& Tervaniemi, 2001; Brattico, Tervaniemi, Näätänen, \& Peretz, 2006; Koelsch, Schröger, \& Gunter, 2002). A substantive difference between tonality and meter is that, although some form of tonality is universal across musical cultures (Krumhansl \& Cuddy, 2010), its specific form is not innate but must be acquired through exposure (Trainor \& Corrigall, 2010).

The effects of pitch and temporal structure are not limited to their respective dimensions, but can influence their integration. In general, having a coherent pitch-time structure (i.e., accent patterns in both dimensions suggesting the same grouping) enhances time judgments (Boltz, 1992, 1995, 1998, 1999), as well as detection of pitch and temporal changes (Brown \& Boltz, 2002; Jones, Boltz, \& Kidd, 1982; Monahan, Kendall, \& Carterette, 1987), melody recognition (Jones \& Ralston, 1991), and production (Jones \& Pfordresher, 1997; Pfordresher, 2003). However, more recent research has reported that the presence of hierarchical structure in one dimension can make it more salient at the expense of another dimension. Prince, Schmuckler, \& Thompson (2009) found that confirming temporal expectancies (playing a note exactly when the listener expects to hear it) only improved accuracy on a pitch comparison task when the sequences were atonal (unstructured pitch). When sequences were tonal, these authors reported that confirming or denying temporal expectancies had no effect on performance. Similarly, the influence of harmonic accents (chord changes) on perceived rhythm (Dawe, Platt, \& Racine, 1993, 1994) decreases for atonal patterns (Dawe, Platt, \& Racine, 1995). These authors instructed listeners to indicate the starting point of repeating rhythm patterns, and manipulated the irrelevant temporal position of alternations between two chords. Responses were most consistent when chord changes were congruent with duration accents (the emphasis created by making one note longer than its neighbors), when both cues accented the same event in the sequence. When the sequences were atonal, chord changes no longer influenced judgments.

The more general question of how information from pitch and time combines in music perception has been an area of continual interest (see Krumhans1, 2000; Prince, 2011, for reviews), with unfortunately little consensus on the issue of whether the integration of these dimensions is linear/additive (Palmer \& Krumhansl, 1987a, 1987b) or interactive (Jones, 1987; Jones \& Boltz, 1989). One possible source of contradictory findings is the relative discriminability of pitch and time. A critical step in assessing how stimulus dimensions combine in perception is to assess their relative discriminability (Garner, 1974), because unequal discriminability across dimensions can result in demonstrably independent dimensions functioning in an interactive manner (Garner, 1976; Garner \& Felfoldy, 1970). There are only two studies in the literature on pitch-time integration in music that satisfy this prerequisite (Ellis \& Jones, 2009; Prince, Thompson, \& Schmuckler, 2009).

Prince, Thompson, \& Schmuckler (2009) showed that tonal structure influences the perception of the temporal properties of a probe note following a melody, but not vice versa; this relationship persisted after equalizing the dimensions in terms of discriminability. These authors proposed the concept of dimensional salience to explain these results. A more salient dimension is prioritized in perceptual processing, and contributes more strongly to forming the mental representation of the external stimulus. As a result, the more salient dimension is more likely to interfere with the processing of another dimension, and also less likely to experience interference from a less salient dimension. Importantly, this concept is separate from the issue of psychophysical difficulty, which can lead to demonstrably independent dimensions appearing interactive (Garner \& Felfoldy, 1970; Melara \& Mounts, 1993, 1994).

The only other study to assess baseline discriminability in pitch-time integration comes from Ellis and Jones (2009). These authors equalized the strength of accents induced by pitch leaps 
with those from duration accents to create either a duple (groups of two) or triple (groups of three) metric structure. After this equalization, they combined these accent types in both congruent and incongruent manners and found that pitch leap accents accounted for three times the variance of duration accents. These results contrast with earlier research discounting the role of pitch accents compared with temporal accents in perception (Huron \& Royal, 1996; Monahan, 1993; Monahan \& Carterette, 1985), as well as production (Drake, Dowling, \& Palmer, 1991; Drake \& Palmer, 1993; Pfordresher, 2003; Snyder \& Krumhansl, 2001). Importantly, none of this earlier research addressed the issue of discriminability.

Taken together, these studies motivate an investigation of the role of tonal structure on the relative strength of pitch and temporal grouping cues of equal discriminability. In the context of music, tonality can attenuate the effects of temporal expectancies (Prince, Schmuckler, \& Thompson, 2009), but how might it affect the combination of the pitch and temporal dimensions in metrical grouping? The results of Dawe et al. (1995) suggest that removing tonality could weaken the effect of pitch grouping cues, however their participants were instructed to indicate rhythm patterns only, and there was no baseline equalization of the strength of accents in both dimensions. In the present study, three experiments comprised an exploration of this question. In the first experiment, different sizes of pitch leap and duration accents were tested, to establish equally strong accent levels, both in a tonal and atonal context. In subsequent experiments, participants heard stimuli consisting of sequences of equal-strength accents, combined in both a congruent and an incongruent fashion, and also varying in the presence of tonal structure. Experiment 2 had no specific instructions to attend selectively to one dimension, whereas Experiment 3 manipulated this instruction between subjects.

In all experiments, participants rated the perceived metrical grouping of the stimuli on a 5-point rating scale-a subjective measure instead of an objective test. This choice follows from an established precedent in research on metrical grouping that specifically investigates the respective roles of pitch and time using a rating scale (Ellis \& Jones, 2009; Hannon et al., 2004; Nittono, Bito, Hayashi, Sakata, \& Hori, 2000), a homologous twoalternative forced choice task (Dawe et al., 1994; Thomassen, 1982), or similar subjective reports of metrical structure (Dawe et al., 1993, 1995). The main theoretical test of dimensional salience in this research derives from a synthesis of the two previous studies that equalized the strength of pitch and time prior to combining them (Ellis \& Jones, 2009; Prince, Thompson, \& Schmuckler, 2009). Continuity with these studies was desirable, both of which employed a rating task. Additionally, Ellis and Jones (2009) explained that this methodology extends the magnitude matching paradigm of Stevens and Marks (Marks \& Gescheider, 2002; Stevens \& Marks, 1980), in which participants used the same ordinal scale to rate the dimensions of brightness and loudness (independently). The present research furthers this extension.

A different methodological approach to metrical grouping is to use a tapping task (e.g., Pfordresher, 2003; Povel \& Essens, 1985; Snyder \& Krumhansl, 2001), which ventures into the sensorimotor literature (see Repp, 2005; Repp \& Su, 2013, for reviews) beyond pure perception and thus the purview of the current study. Additionally, the advantage of using a more objective task (in perception or production) comes with the limitation of being an indirect measure of metrical interpretation. Ultimately, the issue comes down to how best to measure participants' perception of meter. The most direct approach is to ask participants exactly that-what meter do they perceive? Establishing continuity with earlier research and the specific focus on perception made a rating task the most appropriate choice, particularly as a first step toward investigating dimensional salience in the context of metrical grouping.

\section{Experiment 1: Baseline Tests}

The goal of Experiment 1 was to determine levels of pitch and duration accents that resulted in equally strong percepts of groupings. In other words, for inducing duple/triple groupings, how big does a pitch leap need to be to be equally strong as a duration accent? Three different levels of pitch leap and duration accent were used to select the closest matching values across dimension. Previous research has derived such values (Ellis \& Jones, 2009), but all durations were below the temporal integration threshold of $200 \mathrm{~ms}$. Below this threshold, changes in duration and intensity (loudness) mutually interfere; accordingly, a duration accent in Ellis and Jones (2009) may have been perceived as an intensity accent. To remove any potential contribution of changes in perceived loudness to the duration accent, all events had durations at or above the temporal integration threshold.

\section{Method}

Participants. There were 12 participants in Experiment 1, with an average age of 29 years $(S D=11.5)$ and an average of 2 years of musical training $(S D=3.1)$. Participants consisted of students at Murdoch University (Australia) and members of the nearby community. Students enrolled in an introductory psychology class received course credit for their participation; others received $\$ 10$ compensation.

Stimuli. All stimuli began with three chords of unequal duration $(1750,250$, and $750 \mathrm{~ms}$, respectively) to prevent a bias toward any particular metric grouping. After the chords, there was a silent gap of 1,250 ms, followed by an isochronous sequence of 24 notes, with an interonset interval of $500 \mathrm{~ms}(120 \mathrm{bpm})$. The total duration of each stimulus (chords and notes) was therefore $16 \mathrm{~s}$. Each sequence contained either a pitch leap accent or a duration accent, but not both. Accents occurred either every two (duple grouping) or three (triple grouping) notes. Each grouping type of both dimensions had three levels of strength: weak, medium, and strong, described below. Stimuli were generated as .wav files in Matlab, Version 7.0 (MathWorks, 2004) and were harmonically rich, consisting of the fundamental frequency and its first three partials (relative energy of $50 \%, 25 \%, 12.5 \%$, and $12.5 \%$, respectively). All frequencies were restricted to the five-octave range of 77.8-2349 Hz, following Krumhansl, Bharucha, and Kessler (1982).

For the trials using pitch leaps as accents, the three-chord prefix was followed by an ascending pitch sequence of 12 notes, which then repeated once ( 24 notes total). Pitch leap accents occurred every two or three notes, in order to induce a duple or triple grouping. Within a group, the notes ascended by a smaller interval. Sequence starting notes were either C3 (130.8 Hz), C\#3 (138.6 $\mathrm{Hz})$, D3 (146.8 Hz), or D\#3 (155.6 Hz). Each note lasted for 500 ms, such that there was no silent gap between notes (i.e., the interstimulus interval was $0 \mathrm{~ms}$ ). 
In the tonal trials, all notes were selected from the major diatonic scale of the first note (e.g., C major). The three-chord prefix served to orient the listener to the musical key of the subsequent 24-note sequence (in musical terms, chords with the harmonic function of I, IV, and V). The pitch accent consisted of a leap between adjacent notes of three, four, or five scale steps; larger scale steps correspond to stronger pitch leap accents. Due to the structure of the major diatonic scale, the absolute size of a given leap was either three or four semitones (three scale step interval, $M=3.5$ ), six or seven semitones (four scale steps, $M=$ 6.1 ), or seven or eight semitones (five scale steps, $M=7.9$ ). ${ }^{1}$ Within a group, adjacent notes ascended by either one or two semitones (base interval, $M=1.7$ ), also varied as necessary to use only diatonic notes. The sequences were clearly tonal-the average maximum key correlation (MKC) using the Krumhansl-Schmuckler key-finding algorithm (Krumhansl, 1990; Krumhansl \& Schmuckler, 1986) was .87 $(S D=.03)$; without the preceding chords, the mean MKC was .75 $(S D=.08)$. Figure 1a depicts an example sequence suggesting a duple grouping, in the key of $\mathrm{C}$ major. Figure $1 \mathrm{~b}$ shows a tonal example with a triple grouping, also in a $\mathrm{C}$ major tonality. Example stimuli from all experiments are available online as supplemental material.

The atonal trials were designed to prevent the establishment of any musical key (thus atonal). The three starting chords were the same as those in the tonal trials, but four critical notes were shifted up or down by one semitone (smallest possible interval in Western music) so to destroy its tonality. Within a given scale step type (three, four, or five), the atonal trials had exactly the same number and size of intervals as the tonal trials, such that the theoretical pitch accent strength would match across tonality. The difference was in the placement of these intervals, which was manipulated such that the notes did not fall into any one musical key (MKC $M=.46, S D=.06$; without the preceding chords, $M=.50, S D=$ $.17)$. Figure 1c shows an example sequence suggesting a duple grouping, starting on the note $\mathrm{C}$. Figure 1d shows a triple grouping example, also starting on $\mathrm{C}$.

Sequences with duration accents also had the same chords as the pitch accent trials, with half being tonal and the other half atonal. After the chords, the sequences were monotonic (same pitch throughout). In place of the pitch accent, there was a duration accent on one of every two (duple grouping) or three (triple grouping) notes. Within a group, notes lasted for $200 \mathrm{~ms}$ (base duration), whereas the accented note lasted for either 250, 333, or $450 \mathrm{~ms}$. Sequences remained isochronous (equal interonset interval), but the gap between notes varied as a function of their duration.

In sum, the design was a fully crossed $2 \times 2 \times 2 \times 3 \times 4$ (Dimension [pitch, time] $\times$ Grouping [duple, triple] $\times$ Tonality [tonal, atonal] $\times$ Strength [weak, medium, strong] $\times$ Starting Pitch [C3, C\#3, D3, D\#3]) design, giving 96 unique conditions. Participants did each condition twice (in random order), yielding a total of 192 trials. There were two expected findings-first, a main effect of grouping, because triple groupings should be rated differently (higher) than duple groupings. Second, participants should rate sequences as higher (more triple) with increasing strength of triple grouping accents, but lower (more duple) with increasing strength of duple grouping accents. Thus, there should be a Grouping $\times$ Strength interaction.
Apparatus. The experiment ran on a personal computer with the Windows XP operating system. The experimental interface was programmed in Matlab, Version 7.0, using the Psychophysics toolbox (Brainard, 1997). Participants heard the sequences over Sennheiser HD280 Pro headphones, alone in a quiet room.

Procedure. Participants gave informed consent and completed a background questionnaire on their musical experience. The experimenter guided each participant through four practice trials, which consisted of hearing an example sequence and entering a rating on a scale from 1 (strong duple) to 5 (strong triple), indicating how the sequence sounded to them. The experimenter answered any remaining questions and commenced the full version of the experiment (192 trials). After completing the experiment, participants received a debriefing on its purpose and methodology. The entire procedure took approximately one hour.

\section{Results}

There was a high level of agreement across participants in their perceived grouping ratings, with an average intersubject correlation of $.70(S D=.10)$. Participants' ratings were then averaged across the four starting pitches and two repetitions, yielding 24 data points per participant (from the original 192 trials). These ratings were analyzed with a repeated-measures analysis of variance (ANOVA) with the within-subjects factors of $2 \times 2 \times 3 \times$ 3 (Dimension $\times$ Grouping $\times$ Tonality $\times$ Strength), following the design described in the Method section.

The ANOVA revealed slight sphericity violations for Tonality $\times$ Strength (Mauchly's $p=.042)$, Grouping $\times$ Strength $(p=$ $.030)$, and Tonality $\times$ Grouping $\times$ Strength $(p=.037)$. These violations disappear when excluding the participant with the lowest intersubject correlation ( $r=.50 ; 2 S D$ below the mean). The pattern of findings remained the same with or without these data, thus the participant's data were retained in all analyses. Further, using the Greenhouse-Geisser correction (with all participants) did not change any of the results for any experiment. Accordingly, all analyses used the more conventional reporting of degrees of freedom and original $p$ values. There was no main effect of Dimension, $F(1,11)=1.18, p=.301, \eta^{2}<.01$, indicating that participants were equally likely to rate sequences as duple or triple whether or not the accent type was a pitch leap or duration. ${ }^{2}$ There was an expected main effect of Grouping, $F(1,11)=256.88, p<$ $.001, \eta^{2}=.85$, because participants rated duple sequences lower (more duple) than triple sequences. There was no main effect of tonality, $F(1,11)<1, p=n s$, meaning that, overall, the presence or absence of tonality did not bias participants to rate sequences as more duple or triple. There was a weak but unanticipated main effect of Strength, $F(2,22)=4.34, p=.026, \eta^{2}<.01$, because there was a slight trend toward more triple ratings with higher levels of grouping strength. There is no obvious explanation for this result other than a potential ceiling effect with the triple groupings. Because this effect has no direct bearing on the theoretical question under investigation, it will not be discussed further. The only other significant effect was the expected Group-

\footnotetext{
${ }^{1}$ Note that stimuli used only whole number intervals; the mean is provided for convenience of comparison.

${ }^{2}$ All eta-squared values are full eta-squared (i.e., $\mathrm{SS}_{\text {effect }} / \mathrm{SS}_{\text {total }}$ ), not partial eta-squared, because the latter measure inflates the reported value.
} 
a

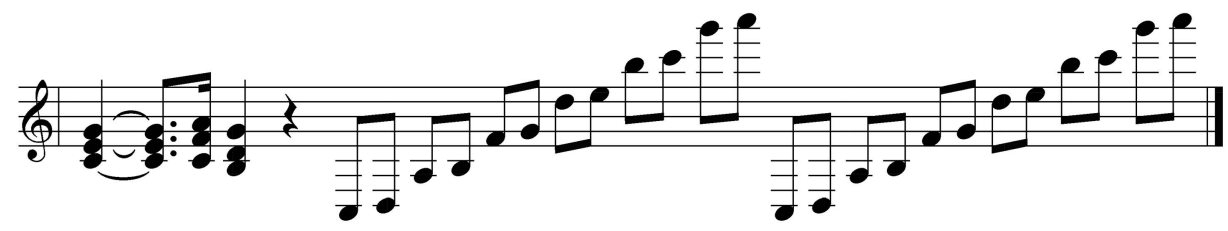

b

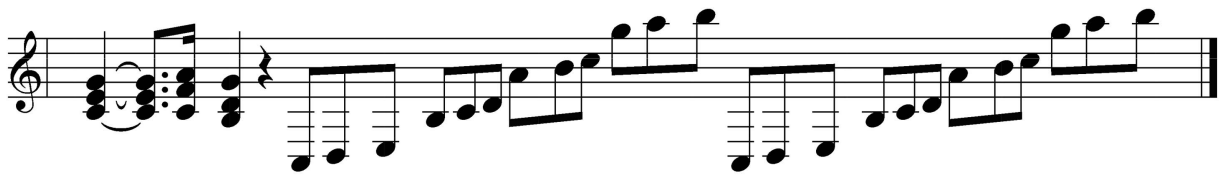

c

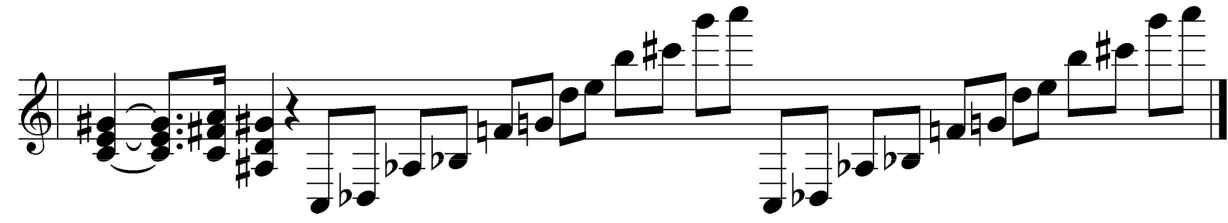

d

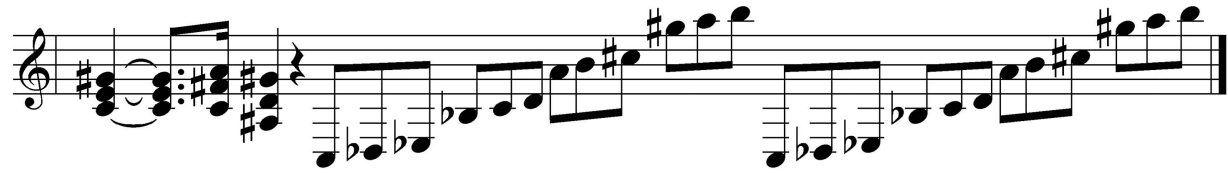

Figure 1. Example sequences with pitch leap accents of five scale steps, including irrelevant three-chord prefix. Tonal sequence, duple grouping (accent every two notes) (a); tonal sequence, triple grouping (accent every three notes) (b); atonal sequence, duple grouping (c); and atonal sequence, triple grouping (d).

ing $\times$ Strength interaction, $F(2,22)=18.01, p<.001, \eta^{2}=.02$, reflecting the important fact that the effect of strength went in opposite directions for different groupings. Consistent with the rating scale, stronger duple groupings gave lower numerical ratings (more duple), whereas stronger triple groupings gave higher numerical ratings (more triple). Figure 2 displays this pattern, for pitch and time separately. No other interactions were significant.

Because the main goal of Experiment 1 was to establish equal levels of accent strength across dimension, there were additional analyses of dimension, grouping, and tonality, despite their lack of interaction. Confidence interval comparisons (see Table 1) revealed that the best match of accent strength across dimension was the five scale step level (pitch leap accent) and $333 \mathrm{~ms}$ (duration accent). For duple groupings, five scale steps gave a mean rating of 1.30 , and $333 \mathrm{~ms}$ (duration) gave 1.28. For triple groupings, five scale steps (pitch) yielded 4.57; $333 \mathrm{~ms}$ (time) was 4.66. These levels differed significantly from lower grouping levels (three scale steps and $250 \mathrm{~ms}$ ).

\section{Discussion}

Experiment 1 provided levels of equal strength for pitch leap accents and duration accents in both tonal and atonal sequences, and gave two main findings. First, varying the structural characteristic of tonality did not influence perceived grouping based on pitch or temporal surface cues in baseline sequences. In sequences with no temporal variation, the strength of pitch leap accents was the same regardless of their level of tonality. Similarly, the tonality of a chord prefix to a monotonic sequence did not affect listeners' ease of extracting duration grouping accents. Stated differently, the presence or absence of pitch structure did not change the effectiveness of pitch leap and duration accents when presented in isolation (baseline conditions). This finding is consistent with Prince, Thompson, \& Schmuckler (2009), who found that the tonal stability of a probe tone biases judgments of whether it is on or off the beat, but without any effect on discriminability (instead, purely response bias). It also concurs with Prince, Schmuckler, and Thompson (2009), who found that a pitch height comparison task was equally difficult for both tonal and atonal sequences.

Second, using only durations above the temporal integration threshold of $200 \mathrm{~ms}$ gave equivalent results to research using a shorter base duration of $60 \mathrm{~ms}$ (Ellis \& Jones, 2009). Ellis and Jones (2009) found that duration accents of $100 \mathrm{~ms}$ gave equivalent grouping strength to a five semitone pitch leap (base 


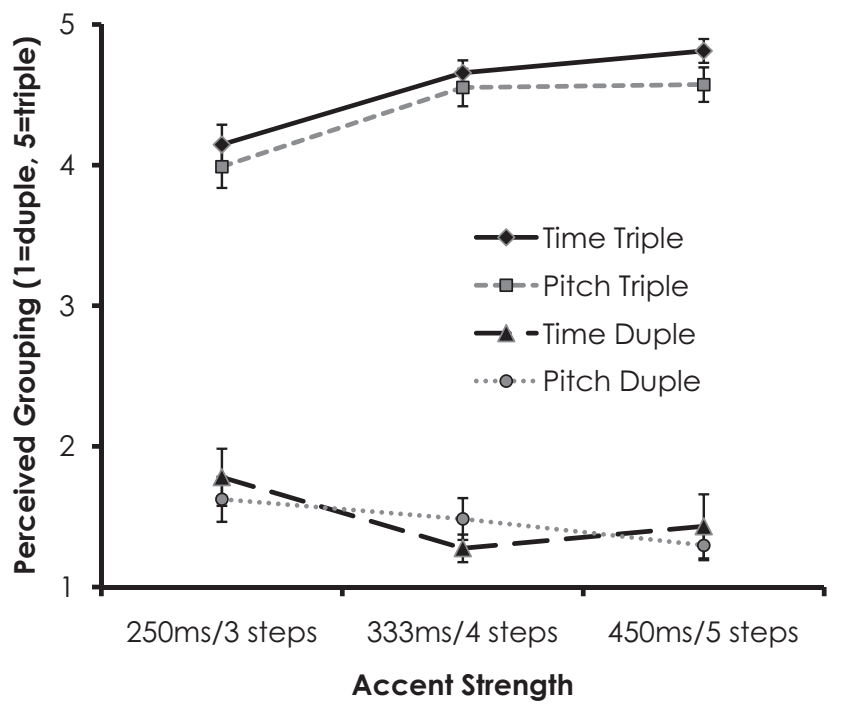

Figure 2. Perceived grouping of triple and duple accents using pitch leap and duration accents. The $x$-axis indicates the accent size (duration of accented note in group or scale step size between groups). Duration values are the length of the accented note; all other notes in a group were 200-ms long. The $y$-axis indicates the perceived grouping, where lower numbers correspond to duple groupings and higher numbers to triple groupings. Error bars are standard error of the mean.

interval of one semitone). Converting these values to Weber fractions (WF) gives .67 (duration) and 4 (pitch leap). In the current study, the 333-ms duration accent (200 ms base) also corresponds to a WF of .67 , and the equally strong five scale step (one step base) pitch accent gives a WF of 4 . These equalized values of accent strength in the current experiment have exactly the same WFs as Ellis and Jones, suggesting that the relative strength of duration and pitch leap accents may remain constant across multiple base durations. This accordance has the notable limitation that the scale step size in the current study did not equate to a constant semitone size (as used in Ellis and Jones). Converting the scale steps to their average absolute size (7.9 and 1.7 semitones) gives a slightly different WF of 3.41. Additionally, the semitone size of pitch intervals was variable in the present study, in order to accommodate the construction of diatonic sequences (cf. Method), necessitating further caution in interpreting this finding. Regardless, it seems unlikely that any perceived changes in loudness from duration accents below the temporal integration threshold had any sizable influence on earlier findings, at least when tested in baseline conditions. Following this related thread of determining the exact nature of the relationship between pitch leap, intensity, and duration accents at various base durations and WFs would be a useful extension of this literature. The main goal of this experiment, however, was to determine the relative sizes of pitch leap and duration accents needed to result in equally strong percepts of metrical grouping while ruling out the potential contribution of the temporal integration threshold to duration accents. This baseline experiment sets the stage for the primary question at hand-How does tonality affect the combination of both accent types in metrical grouping?

\section{Experiment 2: Combining Pitch and Duration Accents}

Having determined what sizes of pitch leap accent and duration accent result in equally strong perceived metrical groupings (Experiment 1), the sequences of Experiment 2 combined these accent types, such that participants heard sequences with both pitch leap accents and duration accents. For each dimension, there were three levels of accent-duple, neutral (accent every six notes), and triple. A $3 \times 3$ factorial combination of the accent levels enables testing how congruent (e.g., duple-duple) and incongruent (e.g., triple-duple) accent patterns affect perceived metrical grouping. In particular, it is possible to test if-once combined-one dimension is more effective than the other dimension, despite being equally strong when presented in isolation (Experiment 1). For example, when the pattern has a duple pattern of duration accents and a triple pattern of pitch leap accents, which prevails? Previous research that used this design (Ellis \& Jones, 2009) has suggested that pitch accents should be more powerful.

Of course, the manipulation of greater theoretical interest is that of tonality. There are several possible outcomes of this manipulation; the first is that pitch leap and duration accents function no differently for tonal and atonal sequences (null hypothesis). That is, one dimension may be more powerful than the other, but unaffected by tonality. The second potential result is that tonality provides a framework that enhances the ability to extract grouping accents in general, regardless of the dimension in which the accent is presented, such that tonal sequences aid the processing of accents in both pitch and time (a "more structure is better" hypothesis). The third possibility is that tonal sequences enhance the strength of pitch leap accents, whereas atonal sequences benefit duration accents (dimensional salience hypothesis). Of these hypotheses, the second is the least likely-tonality did not affect the strength of accents in the baseline conditions of Experiment 1, so there is little reason to expect it to influence the perception of accents when the dimensions are combined.

Table 1

Confidence Intervals of Accent Levels Tested in Experiment 1

\begin{tabular}{|c|c|c|c|c|c|}
\hline \multirow[b]{2}{*}{ Dimension } & \multirow[b]{2}{*}{ Grouping } & \multirow[b]{2}{*}{ Level } & \multirow[b]{2}{*}{$M$} & \multicolumn{2}{|c|}{$\begin{array}{l}\text { Confidence } \\
\text { interval }\end{array}$} \\
\hline & & & & $\begin{array}{l}\text { Lower } \\
\text { bound }\end{array}$ & $\begin{array}{l}\text { Upper } \\
\text { bound }\end{array}$ \\
\hline \multirow[t]{6}{*}{ Pitch } & \multirow[t]{3}{*}{ Duple } & 1 (three steps) & 1.63 & 1.27 & 1.98 \\
\hline & & 2 (four steps) & 1.48 & 1.16 & 1.81 \\
\hline & & 3 (five steps) & 1.30 & 1.07 & 1.53 \\
\hline & \multirow[t]{3}{*}{ Triple } & 1 (three steps) & 3.99 & 3.66 & 4.32 \\
\hline & & 2 (four steps) & 4.55 & 4.26 & 4.85 \\
\hline & & 3 (five steps) & 4.57 & 4.30 & 4.84 \\
\hline \multirow{6}{*}{ Time } & \multirow{3}{*}{ Duple } & $1(250 \mathrm{~ms})$ & 1.78 & 1.33 & 2.23 \\
\hline & & 2 (333 ms) & 1.28 & 1.06 & 1.49 \\
\hline & & $3(450 \mathrm{~ms})$ & 1.43 & 0.93 & 1.93 \\
\hline & \multirow[t]{3}{*}{ Triple } & $1(250 \mathrm{~ms})$ & 4.15 & 3.83 & 4.46 \\
\hline & & 2 (333 ms) & 4.66 & 4.46 & 4.85 \\
\hline & & 3 (450 ms) & 4.81 & 4.63 & 5.00 \\
\hline
\end{tabular}

Note. Values in bold face are the levels chosen for subsequent experiments. 


\section{Method}

Participants. A new set of 12 listeners participated in Experiment 2. These participants were similar in age $(M=28.4$ years, $S D=12.2)$ and musical training $(M=2.3, S D=3.3)$.

Stimuli. New sequences were created in Experiment 2, based on the size of pitch leap accent (five scale steps) and duration accent $(333 \mathrm{~ms})$ selected from Experiment 1. In addition to the duple and triple groupings, there was a neutral grouping that had an accent on every sixth note. This grouping was labeled neutral because it could be heard as either two triple groups or three duple groups, and follows Ellis and Jones (2009). Sequences were created in the same manner as Experiment 1, except that different groupings of the selected pitch and duration accent were recombined to create congruent, unbiased (a neutral grouping in one or both dimensions), and incongruent groupings. Accordingly, the stimuli varied the following variables in a factorial manner: pitch grouping (duple, neutral, triple), time grouping (duple, neutral, triple), and tonality (tonal, atonal). Having equal observations per condition while maintaining a manageable number of trials for each participant required using only three starting pitches for each condition: C3, C\#3, and D3 (discarding the D\#3 from Experiment 1). Crossing three pitch groupings with three time groupings, two levels of tonality, and three starting pitches resulted in 54 stimuli. Each participant did three blocks, giving 162 trials total. All other aspects of the stimuli were the same as Experiment 1.

Apparatus. The apparatus were the same as Experiment 1.

Procedure. The procedure was the same as Experiment 1. Practice trials included only congruent trials (i.e., both pitch and duration accents suggested either a duple or a triple grouping). These trials crossed tonal/atonal sequences with duple/triple groupings.

\section{Results}

Ratings were consistent across participants, with an average intersubject correlation of $.53(S D=.09)$. As in Experiment 1 ,

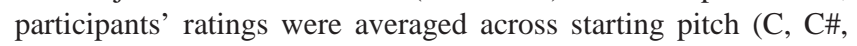
and $\mathrm{D})$ and block $(1,2$, and 3$)$ prior to subjecting the data to a $3 \times$ $3 \times 2$ (Pitch Grouping $\times$ Time Grouping $\times$ Tonality) repeatedmeasures ANOVA. A preliminary ANOVA added block as a within-subjects variable. It exerted neither a main effect nor any interactions, and was therefore omitted from the main analysis presented below. As expected, there were robust effects of pitch grouping, $F(2,22)=84.93, p<.001, \eta^{2}=.56$, and time grouping, $F(2,22)=31.83, p<.001, \eta^{2}=.19$, but not tonality, $F(1,11)<1, p=n s$. There was a Pitch Grouping $\times$ Time Grouping interaction, $F(4,44)=8.77, p<.001, \eta^{2}=.03$. Figure 3 a displays this interaction, showing that participants differentiated more between time grouping levels at the neutral pitch grouping level than at other levels of pitch grouping (i.e., the slope is steeper for pitch neutral).

The only other significant interactions were Pitch Grouping $\times$ Tonality, $F(2,22)=7.88, p=.003, \eta^{2}=.01$, and Time Grouping $\times$ Tonality, $F(2,22)=7.82, p=.003, \eta^{2}=.01$. There were two additional repeated-measures ANOVAs (one for tonal trials, one for atonal) to explore these interactions, both of which had the within-subjects variables of pitch grouping and time grouping. The interaction occurred because the effect size of pitch grouping was .64 in the tonal trials but only .49 in the atonal trials. Conversely,
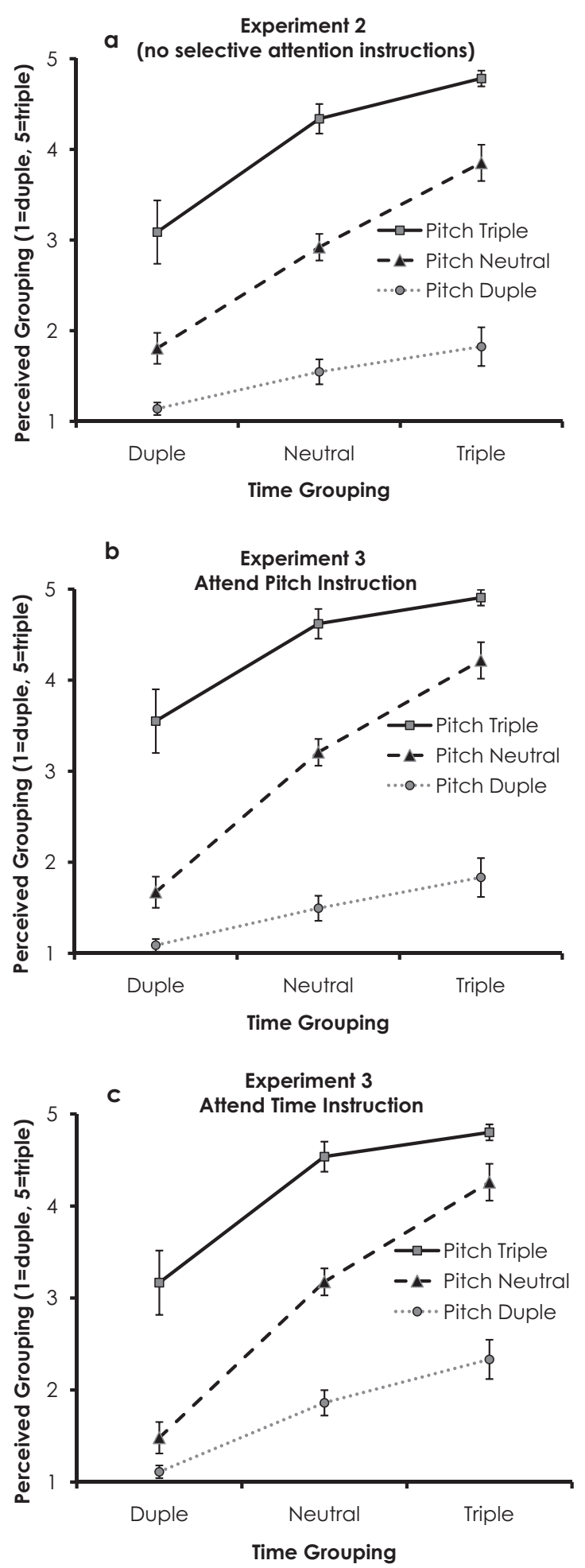

Figure 3. The Pitch Grouping $\times$ Time Grouping interaction across experiment. The $x$-axis represents the duration accent pattern; series are patterns of pitch accent. Experiment 2, with no instructions to attend either dimension (a); Experiment 3, attend pitch participant group (b); and Experiment 3 , attend time participant group (c). Error bars are standard error of the mean. 
time grouping had a larger effect size in atonal trials (.24) than in tonal trials (.14). That is, tonality magnified the contribution of pitch accents and attenuated that of duration accents.

Because effect sizes describe the percent variance accounted for by each variable, they do not indicate the absolute size of the effects. It is possible that both pitch accents and duration accents were stronger in the tonal trials (the "more structure is better" hypothesis), but that the pitch dimension benefited more, yielding the observed interaction. Effect size analyses therefore cannot speak to this issue. However, raw difference scores between duple and triple grouping conditions enable examination of this question, because they represent absolute values rather than the proportion of total variance. Averaging across time grouping levels, subtracting the mean rating for triple pitch grouping levels from the mean rating of duple pitch grouping levels gives a raw difference score representing the strength of pitch grouping cues. The complementary calculation provides the strength of time grouping cues (time triple minus time duple, after averaging across pitch levels). Figure 4a shows these difference scores, separately for tonal and atonal trials. It depicts how the influence of pitch leap accents declines when sequences are atonal (smaller difference score), whereas the effect of duration accents increases for these sequences (larger difference score). A $2 \times 2$ (Dimension $\times$ Tonality) repeatedmeasures ANOVA of these difference scores thus recovered not only a main effect of dimension, $F(1,11)=5.73, p=.036, \eta^{2}=$ .32 (pitch was stronger overall), but also an interaction, $F(1,11)=$ 91.05, $p<.001, \eta^{2}=.04$. Tonality was not significant as a main effect in this analysis, $F(1,11)=2.03, p=.181, \eta^{2}<.01$. An additional ANOVA included block as a factor, and again found neither a main effect nor an interaction with any other variable. Further exploring the Dimension $\times$ Tonality interaction with twotailed paired $t$ tests $^{3}$ revealed that atonal and tonal trials differed significantly for both pitch leap accents, $t(11)=5.37, p<.001$, and duration accents, $t(11)=4.30, p=.003$. Tonality did not benefit both accent types, but selectively boosted the effectiveness of pitch leap accents at the expense of duration accents.

\section{Discussion}

In Experiment 2, pitch leap accents and duration accents were combined in individual sequences, forming sequences with congruent, unbiased, and incongruent grouping cues across dimension. Despite equating the strength of accents across dimension (Experiment 1), pitch accents nonetheless accounted for three times the variance that duration accents did. The Pitch Grouping $\times$ Time Grouping interaction occurred because the effect of one dimension was larger when the other dimension was neutral. The more intriguing results come from the interaction of tonality with both pitch and duration accents: tonality enhanced the effect of pitch accents and reduced the influence of duration accents. These data therefore ruled out the null hypothesis of no effect of tonality, and detracted further from the notion of tonality providing an overall benefit to extracting any type of accent (second hypothesis). Instead, and in accordance with the last (dimensional salience) hypothesis, tonality benefited selectively the dimension for which it provides an organizational framework, namely, pitch.

Previous work on metrical grouping also found that recombining pitch leap and duration accents equalized for strength in a baseline experiment resulted in a dominance of pitch (Ellis \&
Jones, 2009). Specifically, pitch accounted for three times as much variance as time did $\left(\eta^{2}=.51\right.$ and .17 , respectively), using only atonal sequences. In the atonal trials of the current study-arguably the most comparable condition between studies - the advantage of pitch was somewhat smaller in that it accounted for (only) twice the variance of time $\left(\eta^{2}=.49\right.$ and .24 , respectively). If using durations below the temporal integration threshold inflated the contribution of duration accents to grouping (although Experiment 1 downplays this possibility), then one would predict that using durations above this threshold would eliminate this benefit. That is, pitch should account for more than three times the variance of time when using longer base durations. However, the current study's finding of a smaller advantage of pitch in atonal trials suggests exactly the opposite: that the strength of pitch accents was actually hampered by exceeding the temporal integration threshold. This interpretation is speculative, particularly because of the remaining methodological differences between Experiment 2 and Ellis and Jones (2009).

The most obvious of these differences is the variable size of the pitch interval between adjacent notes in the present study. Instead of one semitone intervals within a group (or five semitones between groups), the current experiments used a wider variety of step sizes: one or two semitones within a group and seven or eight between a group (when using the five scale step accent size). A byproduct of this variability is that a wider diversity of pitch classes occurred in the present study $(M=7.5$ unique pitch classes in any given sequence vs. $M=5$ unique pitch classes in Ellis and Jones, 2009). Another difference is the chord prefix before the sequences, although there is no intuitive mechanism by which it could affect the relative strength of these accent types in the subsequent sequence. Nevertheless, the potential effect of these methodological differences remains a question for future research.

The more interesting finding of Experiment 2 is how tonality influenced the relative strength of pitch leap and duration accents. For tonal trials, pitch accents were nearly four times stronger than time $\left(\eta^{2}=.64\right.$ and .14 , respectively), but only twice as strong in the atonal trials $\left(\eta^{2}=.49\right.$ and .24$)$. These sequences were carefully constructed so to avoid any difference between tonal and atonal sequences (other than their tonality, of course). In particular, the size and distribution of intervals was equal for tonal and atonal sequences, the chord prefixes had only minute (but tonally critical) changes, the presence/absence of tonality was not predictive of the pitch groupings, and no group boundaries coincided with a tonal accent. In short, tonality had nothing to do with grouping in these sequences; moreover, as an abstract organizational principle of musical syntax, its presence or absence is irrelevant to the surface features of music such as pitch leaps and duration accents. Nonetheless, tonality increased the strength of pitch accents and decreased the contribution of duration accents. This finding complements Prince, Schmuckler, and Thompson's (2009) report that violating temporal expectancies affected pitch height comparisons only when the (irrelevant) intervening sequences were atonal, but not when the sequences were tonal. It also aligns with Dawe et al. (1995), who found that chord changes were ineffective as rhythmic cues for atonal sequences.

${ }^{3}$ Bonferroni corrections were applied to all $t$ tests. 

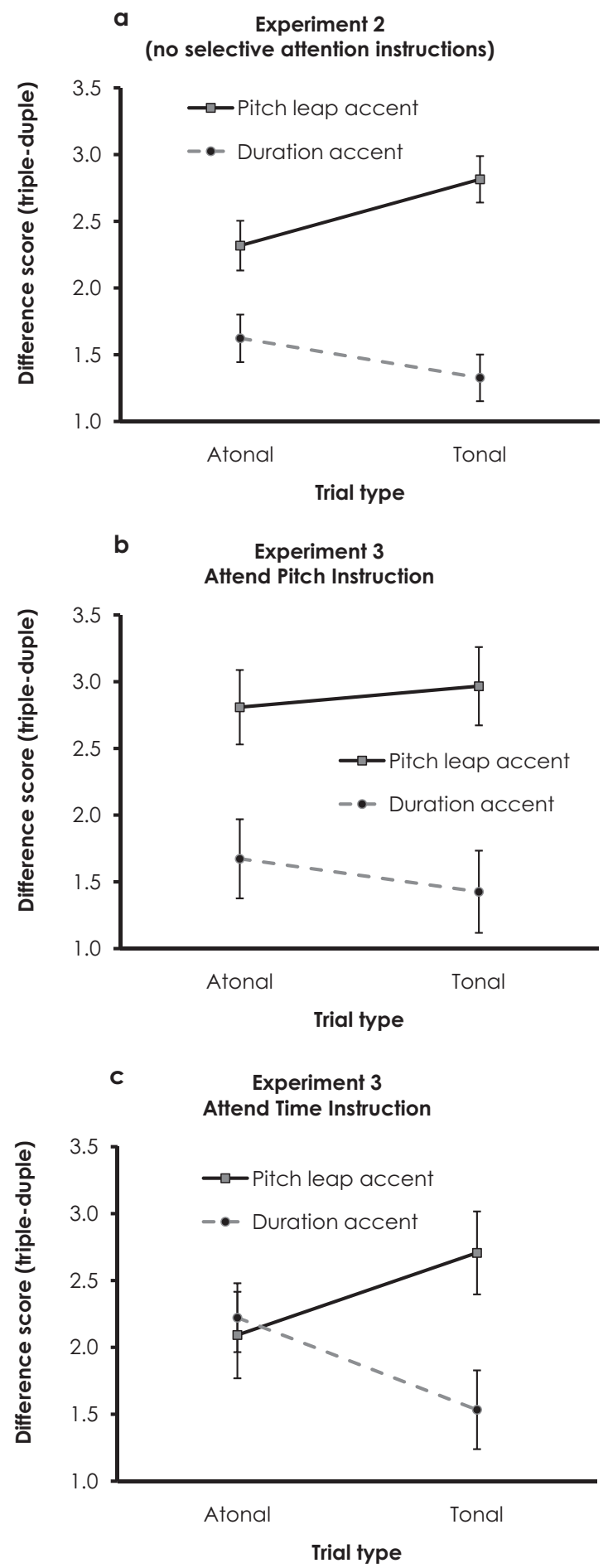

Figure 4. Difference score of perceived grouping (mean triple grouping rating minus mean duple grouping rating) as a function of tonality and dimension. The $x$-axis shows whether sequences were tonal or atonal, and series denote the accent type (pitch leap or duration). Higher scores indicate a more effective accent cue (greater rating difference between triple and duple groupings). Experiment 2, with no instructions to attend either dimension (a); Experiment 3, attend pitch participant group (b); and Experiment 3, attend time participant group (c). Error bars are standard error of the mean.
Respecting a learned organizational framework increases the informative value of a dimension. For example, tonality provides a structure that listeners use to encode a musical sequence (Bharucha \& Krumhans1, 1983; Boltz, 1989a; Cuddy, Cohen, \& Mewhort, 1981; Krumhansl, 1990). By providing this structure, the consequently more useful dimension of pitch becomes more salient and is prioritized in perceptual processing (Prince \& Pfordresher, 2012; Prince, Thompson, \& Schmuckler, 2009). This prioritization means that all cues of this dimension (in this case, pitch leap accents) are more influential in perceptual processing, at the expense of cues in other dimensions (e.g., time). In the current experiment, pitch became more salient in tonal sequences, increasing the contribution of pitch accents to listeners' perceived grouping ratings, as well as decreasing the weighting of duration accents. Tonality is specific to music, but the same principle of passive and culture-specific learning affecting dimensional processing also arises in language processing-cultural background influences the relative strength of pitch and time accents in language (Cumming, 2010; Iversen, Patel, \& Ohgushi, 2008; Yoshida et al., 2010, but see Hay \& Diehl, 2007).

Another possible explanation of the effects of tonality in Experiment 2 is that listeners simply paid more attention to pitch when the sequences were tonal. Listeners did not receive any instructions to privilege one dimension over another, but it is possible that they chose to attend more to pitch when the sequences were tonal. The findings of Experiment 1 argue against this interpretation, because tonality affected neither the strength of pitch nor the duration accents (when tested separately in baseline conditions). Further, one could in theory also argue the oppositethat when sequences were atonal, they would violate listeners' expectations of a normal tonal sequence, in turn drawing more attention to pitch. Obviously, the data do not support this latter explanation, but it bears mentioning because it reveals that both explanations are equally arbitrary a priori. In any case, the role of attention is uncertain in this experiment. Clarifying this issue was the goal of Experiment 3.

\section{Experiment 3: Selective Attention in Grouping}

Experiment 2 found that the presence of tonality exaggerated the influence of pitch accents at the expense of duration accents, but the exact cause of this effect was unclear. Specifically, effects of tonality may have been caused by listeners attending more to pitch when sequences were tonal, or by increased salience of this dimension. In Experiment 3, participants received selective attention instructions to manipulate explicitly their attention toward one dimension and away from the other. If the effects of tonality are artifacts of attentional focus, then they should disappear when listeners consciously direct their attention to one dimension. There were two groups of participants in Experiment 3-one set instructed to attend selectively to pitch accents, the other to duration accents (i.e., manipulated between-subjects). In every other way, the design of the current experiment was the same as Experiment 2.

Selective attention is an effective technique to modify auditory processing (see Snyder, Gregg, Weintraub, \& Alain, 2012, for a review). With specific regard to tonality, brain responses to violations of harmonic expectancies in chord sequences are larger and faster when the listener is actively attending the stimuli (Loui, 
Grent-'t-Jong, Torpey, \& Woldorff, 2005). Although harmonic expectancies are not the same as tonality (chord sequences could be tonal without having expectancies), establishing a key area (i.e., tonality) is a prerequisite for the formation of harmonic expectancies. Lastly, selective attention instructions are effective at changing the relative contribution of manipulations of tonality and meter to melodic goodness ratings (Prince, 2011). In particular, interactions between pitch and time were stronger in that study when the dimensions were more equally matched in their main effect size (eta-squared).

A dimensional salience hypothesis predicts that pitch accents should be more influential for tonal sequences than atonal sequences regardless of attentional instruction, so the current experiment should replicate the findings of Experiment 2 for both experimental groups. Neither attentional nor psychophysical factors (cf. Experiment 1) could explain such results. The only remaining explanation would be that the effects of tonality on metrical grouping represent changes in dimensional salience-the priority of pitch or time in perceptual process of forming the mental representation of a given sequence.

\section{Method}

Participants. There were 24 participants in Experiment 3. The average age was 26.7 years $(S D=11.5)$ and they had, on average, 2.9 years of musical training $(S D=3.9)$.

Stimuli. The stimuli of Experiment 3 were the same as those used in Experiment 2.

Apparatus. Experiment 3 apparatus were the same as the previous experiments.

Procedure. In Experiment 3, half of the participants received instructions to base their ratings on pitch accents (ignore duration accents), whereas the other half were told the opposite. A given participant experienced only one instruction type for the entire experimental session. To ensure that participants understood what exactly they were to attend and ignore, the experimenter explained the concept of pitch accents and duration accents prior to beginning any trials, and played examples of each (using baseline sequences from Experiment 1). As in Experiment 2, the subsequent four practice trials consisted only of congruent pairings of pitch and duration accents. Thus the practice and experimental trials were exactly the same as Experiment 2, except for the addition of the selective attention instructions.

\section{Results}

The average intersubject correlation was $.58(S D=.08)$ for the attend pitch instruction, and $.53(S D=.07)$ for the attend time instruction, again showing consistency across participants. Ratings were again averaged across starting pitch $(\mathrm{C}, \mathrm{C \#}$, and $\mathrm{D})$ and block $(1,2$, and 3), and then entered into a mixed-design ANOVA with the between-subjects variable of instruction (2 levels: attend pitch or attend time). The within-subjects variables were the same as Experiment 2: pitch grouping (three levels: duple, neutral, or triple), time grouping (three levels: duple, neutral, or triple), and tonality (two levels: tonal, atonal). A preliminary ANOVA included block as a within-subjects variable, but it did not exert a main effect, nor did it interact with another variable.

There was no main effect of instruction, $F(1,22)<1, p=n s$, nor was there a main effect of tonality, $F(1,22)<1, p=n s$.
Conversely, there were strong main effects of both pitch grouping, $F(2,44)=143.87, p<.001, \eta^{2}=.51$, and time grouping, $F(2$, 44) $=68.69, p<.001, \eta^{2}=.22$. These effects represent the expected higher ratings (more triple) for triple groupings than duple.

Interestingly, instruction did not interact with pitch grouping, $F(2,44)=1.31, p=.280, \eta^{2}<.01$, nor was there an Instruction $\times$ Time Grouping interaction, $F(2,44)<1, p=n s$. These null results suggest that the perceptual effects of pitch grouping and time grouping were the same for both instruction groups (i.e., the instruction to attend one dimension was ineffective). However, the selective attention instructions may have been more successful at the beginning of the experiment than at the end. When analyzing only the first block of data, there was a marginal Instruction $X$ Pitch Grouping interaction, $F(2,44)=2.68, p=.080, \eta^{2}=.01$, and a significant Instruction $\times$ Time Grouping interaction, $F(2$, $44)=3.50, p=.039, \eta^{2}=.01$, both in the expected direction. These effects shrank in analyses of the third (last) block of participants' data, $F(2,44)=1.13, p=.332, \eta^{2}=.01$, and $F(2$, $44)<1, p=n s$, respectively. The most likely explanation of the failure of the selective attention instructions is the unfortunately commonplace phenomenon of participant fatigue. This explanation is tentative given that there were no significant effects of block in the preliminary analysis.

The Pitch Grouping $\times$ Time Grouping interaction recurred, $F(4$, $88)=21.06, p<.001, \eta^{2}=.04$, depicted in Figure $3 \mathrm{~b}$ and $3 \mathrm{c}$, which replicates Experiment 2. Also as in Experiment 2, tonality interacted with both pitch grouping, $F(2,44)=30.75, p<.001$, $\eta^{2}=.01$ and with time grouping, $F(2,44)=14.48, p<.001$, $\eta^{2}<.01$. These interactions replicated the pattern from Experiment 2, where the effect of pitch grouping was larger in the tonal trials $\left(\eta^{2}=.58\right)$ than the atonal trials $\left(\eta^{2}=.44\right)$, and the reverse for the effect of time grouping $\left(\eta^{2}=.16\right.$ and .29 , respectively). There was no three-way Pitch Grouping $\times$ Time Grouping $\times$ Tonality interaction, $F(4,88)=1.02, p=.402, \eta^{2}<.01$, nor was there a three-way Pitch Grouping $\times$ Time Grouping $\times$ Instruction interaction, $F(4,88)<1, p=n s$.

Although instruction did not interact with pitch grouping or time grouping in two-way interactions, there was a significant Instruction $\times$ Pitch Grouping $\times$ Tonality interaction, $F(2,44)=6.56$, $p<.001, \eta^{2}<.01$, and a marginal Instruction $\times$ Time Grouping $\times$ Tonality interaction, $F(2,44)=2.91, p=.065, \eta^{2}<.01$. The initial mixed ANOVA does not specify the nature of these three-way interactions, nor enable inspection of how effect sizes changed across instruction. Therefore, separate analyses for each instruction explored these interactions and provided a comparison of findings across instruction, using the same within-subjects analysis design of Experiment 2. These analyses are detailed below, but can be summarized as the interactive effect of tonality (as in Experiment 2) being stronger in the attend time instruction than attend pitch. The four-way interaction (between all variables in the analysis) was thankfully not significant, $F(4,88)<1, p=n s$.

Attend pitch instruction. The same $3 \times 3 \times 2$ (Pitch Grouping $\times$ Time Grouping $\times$ Tonality) ANOVA design as in Experiment 2 was used to examine the data from the 12 participants who received the instruction to attend selectively to pitch accents in forming their grouping ratings. Not surprisingly, this analysis revealed significant effects of pitch grouping, $F(2,22)=92.64$, $p<.001, \eta^{2}=.59$, and time grouping, $F(2,22)=25.71, p<$ 
$.001, \eta^{2}=.17$, and an interaction between them, $F(4,44)=14.60$, $p<.001, \eta^{2}=.04$, following the same pattern as the overall analysis immediately above. Of greater interest, the Pitch Grouping $\times$ Tonality interaction was significant, $F(2,22)=17.04, p<$ $.001, \eta^{2}<.01$, as was Time Grouping $\times$ Tonality, $F(2,22)=$ 5.33, $p=.013, \eta^{2}<.01$. The three-way Pitch Grouping $\times$ Time Grouping $\times$ Tonality interaction was not significant, $F(4,44)<1$, $p=n s$. The two-way interactions followed from the overall analysis-pitch grouping had a larger effect in the tonal trials $\left(\eta^{2}=.62\right)$ than the atonal trials $\left(\eta^{2}=.56\right)$, whereas time grouping had a smaller effect in the tonal trials $\left(\eta^{2}=.15\right)$ than the atonal trials $\left(\eta^{2}=.21\right)$. The difference scores as calculated in Experiment 2 revealed a similar, but smaller, pattern (see Figures $4 \mathrm{a}$ and $4 \mathrm{~b}$ ). The $2 \times 2$ (Dimension $\times$ Tonality) repeated-measures ANOVA of the difference scores yielded a main effect of dimension, $F(1$, $11)=5.32, p=.042, \eta^{2}=.28$ (again pitch was stronger overall), and an interaction, $F(1,11)=23.59, p=.001, \eta^{2}=.01$. Tonality was again not significant as a main effect, $F(1,11)=1.57, p=$ .236, $\eta^{2}<.01$. As before, block was not significant as a main effect in an additional ANOVA, nor did it interact with another variable. Finally, the paired two-tailed $t$ test analysis of the difference scores verified that pitch leap accents were stronger for tonal sequences, $t(11)=3.56, p=.009$, and duration accents were stronger for atonal sequences, $t(11)=3.88, p=.005$.

Attend time instruction. The data from the 12 participants who received the instruction to attend selectively to time accents in forming their grouping ratings was analyzed in the same manner as the attend pitch instruction group. Of course, the main effects of pitch grouping, time grouping, and their interaction were again significant, $F(2,22)=55.24, p<.001, \eta^{2}=.43 ; F(2,22)=$ 45.34, $p<.001, \eta^{2}=.27 ; F(4,44)=7.91, p<.001, \eta^{2}=.04$, following the same pattern as the previous analyses. There were two-way Tonality $\times$ Pitch Grouping and Tonality $\times$ Time Grouping interactions, which were stronger than in the attend pitch instruction, $F(2,22)=19.20, p<.001, \eta^{2}=.01 ; F(2,22)=9.62$, $p<.001, \eta^{2}=.01$, respectively. There was no three-way Pitch Grouping $\times$ Time Grouping $\times$ Tonality interaction, $F(4,44)<1$, $p=n s$. As before, the effect size of pitch grouping was larger in the tonal trials $\left(\eta^{2}=.52\right)$ than the atonal trials $\left(\eta^{2}=.31\right)$, and time grouping showed the opposite pattern $\left(\eta^{2}=.17\right.$ and .37 , respectively). Figure $4 \mathrm{c}$ depicts these difference scores, which, when subjected to the $2 \times 2$ (Dimension $\times$ Tonality) repeated-measures ANOVA, revealed no main effect of dimension (in contrast to the attend pitch instruction), $F(1,11)<1, p=n s$, or a main effect of tonality, $F(1,11)<1, p=n s$. The critical interaction remained, $F(1,11)=46.96, p<.001, \eta^{2}=.08$, and when analyzed with two-tailed paired $t$ tests, again showed that tonality magnified the effect of pitch accents, $t(11)=5.58, p<.001$, and attenuated that of duration accents, $t(11)=4.26, p=.003$.

Block effects. For the attend pitch instruction, there were no interactions with block and any other variable, including tonality and dimension, $F(2,22)=2.43, p=.111, \eta^{2}<.01$. Thus, the effects of tonality did not differ across block, despite a nominal trend toward tonality having the strongest effect in Block 2, as shown in Figure 5a. The only significant interaction was Block $\times$ Tonality $\times$ Dimension for the attend time instruction, $F(2,22)=$ $5.86, p=.009, \eta^{2}=.01$. Figure $5 \mathrm{~b}$ depicts this interaction, showing that the effects of tonality were strongest in the first block (i.e., the slopes are steepest in Block 1). This figure also offers support to the participant fatigue explanation of the null Time Grouping $\times$ Instruction interaction reported earlier (third paragraph of the Results section). Specifically, duration accents appear equally effective as pitch accents in Block 1, but not for the remaining blocks. More simply, only the solid lines cross. Nevertheless, block did not interact with dimension, $F(2,22)=2.34$, $p=.119, \eta^{2}<.01$.

\section{Discussion}

One proposed explanation of the pitch-tonality and time- tonality interactions in Experiment 2 was that listeners may have chosen to attend more to pitch when sequences were tonal (see Experiment 2 Discussion). The results of Experiment 3 refute this explanation, because when participants received explicit instructions to attend selectively to one dimension, they had difficulty doing so. The instructions were marginally more successful at the beginning of the experiment, and the Dimension $\times$ Tonality analysis of the raw difference scores showed
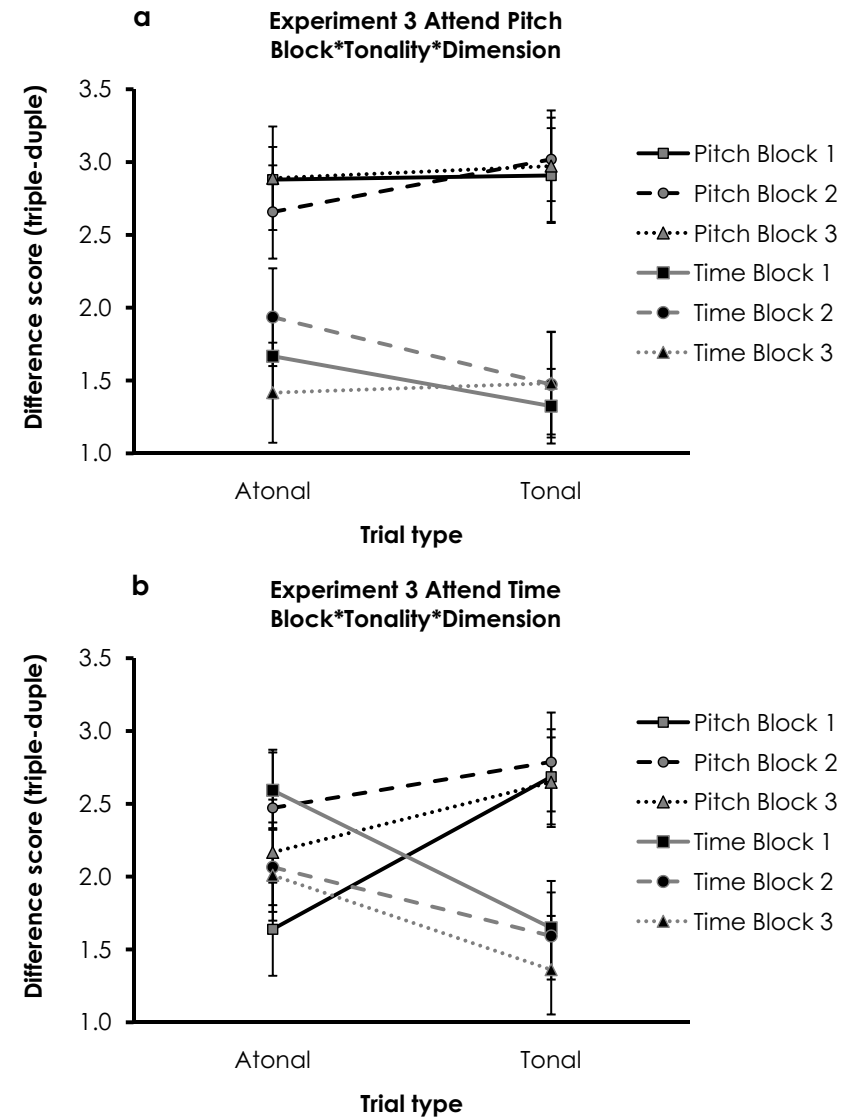

Figure 5. Effect of block on how tonality influenced the strength of pitch and duration accents in Experiment 3. For the attend pitch instruction, this interaction was not significant; the overall effect of tonality is as shown in Figure $4 \mathrm{~b}$ (a). For the attend time instruction, pitch and time accents were equally strong only in the first block (i.e., only the solid lines cross) (b). The effect of tonality on the pitch/duration accent balance remained the same across block, but was nominally largest in Block 1, when selective attention instructions were most successful. Error bars are standard error of the mean. 
that, although pitch accents were stronger overall in the attend pitch condition, they were equal for the attend time condition (compare Figures $4 \mathrm{~b}$ and $4 \mathrm{c}$ ). Therefore, instructions had some measurable effect on ratings, but the effects do not suggest a robust ability to ignore either dimension. This limited effectiveness of intentional direction of attention to either dimension in Experiment 3 undermines the possibility that unintentional allocation of attention explains the results of Experiment 2.

Yet stronger evidence of this point emerges from Figure 5b, which demonstrates that, earlier in the experiment (when the possibility of participant fatigue was lowest and attentional instructions were most effective), the tonality manipulation actually had its strongest effects. That is, variations in dimensional salience invoked by the presence/absence of tonality were actually most apparent when participants were better at ignoring pitch. If the effects of tonality were due to attention, then they should decrease with selective attention success-not increase. To elaborate, any shift of attention induced by tonality should be weakest when participants' selective attention is best, and stronger as fatigue reduces their resistance to its effects. However, the pattern is exactly the opposite of the predictions of an attentional account, dissociating the two processes. This finding strengthens the case for dimensional salience as independent from attention.

Further discrediting an attentional origin of Experiment 2's effects is the replication and extension of the interactions of interest in Experiment 3. Tonal sequences exaggerated the influence of pitch leap accents at the expense of duration accents, whereas atonal sequences decreased the effects of pitch leap accents in favor of duration accents. To be clear, pitch leap accents were always more effective, but were less or more so based on the tonality of the sequences, as described above.

The strength of the Dimensions $\times$ Tonality interactions also varied across instruction, as evidenced by two separate threeway interactions (Instruction $\times$ Pitch Grouping $\times$ Tonality; Instruction $\times$ Time Grouping $\times$ Tonality). These interactions showed that the influence of tonality on the relative effect size of pitch and duration accents was larger for participants instructed to attend solely to duration accents. Consult Figure $4 b$ and $4 \mathrm{c}$ to visualize this effect-in the attend time instructions, the gap between pitch leap and duration accent difference scores changed more from atonal to tonal trials than in the attend pitch instructions. In other words, the slopes are steeper in Figure $4 c$ than $4 b$.

Overall, Experiment 3 replicated the finding of Experiment 2 that the presence of tonality heightened the salience of the pitch dimension as a whole, such that pitch leap accents became more effective despite being exactly the same size in both tonal and atonal sequences. Concomitantly, duration accents became less effective when sequences were tonal, even though they were exactly the same physical size across tonality. These findings were not abolished by instructions to shift attention toward one dimension or another. Instead, they are consistent with a dimensional salience hypothesis (Prince, Schmuckler, \& Thompson, 2009; Prince, Thompson, \& Schmuckler, 2009) that prioritizes a more informative dimension in constructing the mental representation of an external stimulus.

\section{General Discussion}

These three experiments reveal how tonality influences the relative strength of pitch and duration accents on ratings of perceived metrical grouping. Finding pitch leap accents and duration accents of equivalent strength was the goal of Experiment 1. Experiments 2 and 3 recombined these equalized accent types in sequences such that pitch and duration accents were either congruent, unbiased, or incongruent. When recombined, pitch leap accents always predominated over duration accents in their influence on participants' ratings. But more importantly, the advantage of pitch accents was larger when the sequences were tonal and smaller for atonal sequences, whereas duration accents followed the opposite pattern. These results could not be accounted for by psychophysical differences, because they used accents that were equally strong across dimensions (cf. Experiment 1). Experiment 3 ruled out an attentional origin of these effects, showing that the effects of tonality remained when participants had instructions to ignore one dimension.

Failures of selective attention can provide evidence of integral dimensions (Garner, 1974), but definitive conclusions about the separability of dimensions require convergent evidence from different tasks and processes (Garner, 1976). The results of Experiment 3 do not permit strong interpretations of the independent versus interactive nature of pitch and time in music cognition, partly because the instruction manipulation had some observable effects (in early blocks), and also because participant fatigue may have contributed to the small effect sizes. Indeed, auditory selective attention generally becomes more effective with practice, not less (Best, Ozmeral, Kopco, \& Shinn-Cunningham, 2008). Regardless, a critical prerequisite to reaching conclusions about how dimensions combine is ensuring that the dimensions are equally effective when tested separately, in baseline conditions. Other than the current research, the only study to do these baselines in tests of metrical grouping is Ellis and Jones (2009). They also found a dominance of pitch over time, and their methodology corresponds most closely with the atonal sequences of Experiments 1 and 2 in the current findings (they used neither tonal sequences nor selective attention instructions). Interestingly, their analyses of metrical clarity ratings suggested an interactive pattern of pitch-time integration, yet their perceived grouping ratings (as used in the current research) supported an independent relationship.

Combined with the other literature on pitch-time integration, it is clear that attempting to determine if pitch and time are independent or interactive is not the right question. Instead, the more interesting and generally applicable psychological issue is why the dimensions combine in different fashions. Discarding the view of a dichotic classification of these possibilities, several authors have explored how pitch-time integration can vary (Prince, 2011; Prince, Schmuckler, \& Thompson, 2009; Schellenberg, Krysciak, \& Campbell, 2000; Tillmann \& Lebrun-Guillaud, 2006). For example, Schellenberg et al. (2000) mooted the possibility that subjective tasks (e.g., goodness of fit ratings, liking) give rise to interactive patterns, whereas objective tasks (e.g., classification, recall) foster independence. Yet both patterns can occur in both subjective (Boltz, 1989b; Palmer \& Krumhansl, 1987a) and objective (Jones et al., 1982; Smith \& Cuddy, 1989) tasks. Tillmann and Lebrun-Guillaud (2006) proposed that global tasks lead to interactive relations, and local tasks favor independence (see also 
Jones \& Boltz, 1989). Some arguably global tasks can result in independence, and local tasks in interactions Prince, 2011; Prince, Schmuckler, \& Thompson, (2009), but this interpretation requires further exploration.

Another possible explanation of the variations in pitch-time integration comes from the concept of dimensional salience, developed in the context of music perception (Prince, Thompson, \& Schmuckler, 2009), but with more general applicability to other auditory dimensions, task domains, and sensory modalities. What makes a dimension more salient? It is likely that numerous variables influence dimensional salience, but the mechanism with the most support thus far is based on the extent to which it adheres to a learned schema. This concept converges with the fuzzy logical model of perception (FLMP) developed in the context of speech perception, in which stimulus dimensions are weighted in accordance with the degree to which they match a learned prototypical representation of a speech sound (Massaro \& Friedman, 1990; Oden \& Massaro, 1978). There is also some overlap with the TRACE model (McClelland \& Elman, 1986) in that one source of information (e.g., pitch) can influence the sensitivity to another source (e.g., time). However, the interactive-activation nature of the TRACE model (activating higher order units influences lower order, and vice versa) predicts effects of context on perceptual sensitivity (Massaro, 1989), whereas demonstrations of dimensional salience occur only when differences in discriminability are eliminated (via baseline testing). For instance, Prince, Thompson, \& Schmuckler (2009) found that the effects of tonality on temporal classification were in response bias, not discriminability, aligning more with the principles of the FLMP (Massaro, 1989). Cutting's (1986) directed perception model also has relevance because it allows adjustable weightings of information sources, but it also assumes a Boolean additive integration, whereas the current data showed that neither dimension could be ignored entirely. In the current study, the manipulation of adhering to a prototypical structure was accomplished by varying the presence of tonality, the central organizational principle of musical pitch (Krumhansl \& Cuddy, 2010). Adhering to this hierarchical structure makes the dimension of pitch more informative, and more useful as a framework for encoding additional information, such as the duration accents of the present study.

An inherent advantage of pitch over time in Western music has both theoretical (Everett, 2000; Schenker, 1935/1979) and experimental (Hébert \& Peretz, 1997; Krumhansl, 2000; Prince, Thompson, \& Schmuckler, 2009) support. A learned preferential weighting of pitch may occur as the stimuli increasingly resemble Western music — such as using tonal sequences. In the context of visual object identification and categorization, selective attention can increase the discriminability of items along a given stimulus dimension at the expense of another dimension (Nosofsky, 1986). According to Goldstone (1998), this "attentional weighting" of dimensions may occur via perceptual or strategic processes. In the current research, tonality provided neither a perceptual advantage nor a strategic benefit for pitch-it was truly irrelevant to the task. Thus dimensional salience is not simply an outgrowth of attentional processes highlighting pitch in tonal sequences.

Previous research has also shown the influence of tonality in pitch-time integration (Dawe et al., 1995; Prince, Schmuckler, \& Thompson, 2009), and has manipulated meter, the homologous structure in the time dimension (Prince, 2011; Tillmann \& Lebrun-
Guillaud, 2006). Yet other work has explored the role of diversity, or the number of unique categories defined within a dimension (Prince \& Pfordresher, 2012; Sarrazin, Giraudo, \& Pittenger, 2007); research in visual perception has also tested how diversity (quantity) affects dimensional processing (Melara \& Mounts, 1994), but not dimensional salience per se. Tonality and meter are examples of schemas that provide organizational frameworks for use in perceiving musical stimuli specifically, but the applicability of dimensional salience is not limited to this domain-work in visual perception and attention provides convergent evidence of perceptual organization influencing visual processing automatically (De Freitas, Liverence, \& Scholl, 2014; Hermens, Scharnowski, \& Herzog, 2010; Kimchi, 2009; Kimchi, Yeshurun, \& Cohen-Savransky, 2007; Parton, Donnelly, \& Usher, 2001; Russell \& Driver, 2005; Strother \& Kubovy, 2012). Moreover, the concept of dimensional salience fits well with work on asymmetric dependencies in other musical dimensions (Cousineau, Demany, \& Pressnitzer, 2009; Krumhansl \& Iverson, 1992; Gürkan Tekman, 2002; Warrier \& Zatorre, 2002), speech perception (Green, Tomiak, \& Kuhl, 1997; Mullennix \& Pisoni, 1990; Tong, Francis, \& Gandour, 2008), and face perception (Graham \& LaBar, 2007; Karnadewi \& Lipp, 2011; Zhao \& Hayward, 2013).

There are some limitations of these findings that deserve consideration. First, the current study (and previous literature) used only one measure of how strong each dimension was- the perceived grouping rating. Despite the careful procedure of equalizing the dimensions in baseline conditions, a stronger test of relative dimension strength might include some external measure of the effects of pitch and time. For instance, a matching and/or adjustment technique could provide a more sensitive and convergent observation of these effects. Objective measures of processing facilitation (e.g., tapping) in accordance with metrical structure could also be useful.

Second, it is possible that ceiling and floor effects restricted the range of observable effects, particularly when pitch and duration accents were congruent. Perhaps the dimensions were not as equally matched as hoped, qualifying the conclusions on which dimension was stronger. The fact that these results converge so well with previous observations of metrical grouping (Ellis \& Jones, 2009) provides some counterevidence to this criticism. More importantly, however, the most interesting result is not about which dimension is stronger as a main effect but about how the presence of structure manipulates their interaction. In fact, the presence of floor and ceiling effects would only make for a more conservative test of this phenomenon, because the resultant range restriction would compress the raw difference scores for both tonal and atonal trials, underestimating the observed effects across tonality.

Third, in the baseline tests of Experiment 1, sequences had either pitch leap accents or duration accents-not both (by definition). Whereas pitch leaps create a clear grouping such that the first note after a leap begins the group, the interpretation of duration accents is more flexible - it is possible to perceive the longer note as the first or last note of a group (Iversen, Repp, \& Patel, 2009). This flexibility may undermine the strength of duration accents when combined with the unambiguous pitch leap accents. Regardless, this interpretation remains consistent with the concept of dimensional salience - a dimension with more reliable cognitive reference points (in this case, pitch) provides a more robust frame- 
work for encoding stimulus information. In the context of face perception, facial identity is an invariant attribute, functioning as a more stable reference point than facial emotion (Haxby, Hoffman, \& Gobbini, 2000). Accordingly, aspects of facial identity such as sex asymmetrically interfere with judgments of facial emotion (Atkinson, Tipples, Burt, \& Young, 2005).

Fourth, only one tempo (120 bpm, or $500 \mathrm{~ms}$ between notes) was used in the current experiments. Listeners synchronize most easily to (and produce spontaneously) tempos with intervals of 600 ms, but can entrain to a wide range of tempos (McAuley \& Semple, 1999), as long as they remain between the range of 300-1,800 ms apart (Fraisse, 1982). Changing tempo can alter the metrical interpretation of rhythmic sequences (Handel \& Lawson, 1983; London, Himberg, \& Cross, 2009). For instance, Hannon et al. (2004) found that listeners favored interpretations of $3 / 4$ over $6 / 8$ for slower tempos. In the current experiments, the triple grouping would complete a full cycle after 1,500 ms, and the duple grouping would be every $1,000 \mathrm{~ms}$. The duple is closer to the ideal 600-ms interval, but both are well within the range of perceivable tempos. There was no strong evidence of an overall preference for duple versus triple groupings, because the grand mean average rating for each experiment was indistinguishable from the midpoint of 3 on the 1-5 scale (Experiment 1: 2.97, Experiment 2: 2.81, Experiment 3: 2.96 and 2.97). It is unlikely, but, as yet untested, that a different tempo would change the effects of tonality on perceived grouping.

Future research might examine the effects of different types of structure, and in other dimensions. This study varied the presence of tonality, the central organizational principle of musical pitch. Varying the presence of meter (whether sequences conform to a regular pulse or beat) may have similar effects (but cf. Tillmann \& Lebrun-Guillaud, 2006). The dimensional salience framework would predict an affirmative answer, because it does not differentiate between which dimension exhibits greater structure, consistent with Pressing's (1983) notion of cognitive isomorphisms. Both tonality and meter are abstract organizational forms of structure, whereas more surface-based forms of structure may also play a role in dimensional processing (Melara \& Mounts, 1994; Prince \& Pfordresher, 2012; Schellenberg, Stalinski, \& Marks, 2014). It may also be useful to explore the role of training on pitch-time interactions in metrical grouping. Although perceptual tests tend to reveal only quantitative (not qualitative) differences across expertise (Bigand \& Poulin-Charronnat, 2006), it would be reassuring to verify that metrical grouping is not an exception. Another line of inquiry could explore how pitch-time integration changes in contexts where the dimensions are purposely unbalanced. Garnertype interference may occur (Garner, 1974), or perhaps a different pattern could emerge when dealing with musical sequences, because they provide their own self-contained context. Whatever the application, investigations of dimensional salience must first equalize the dimensions in terms of their baseline discriminability (cf. Experiment 1, Ellis \& Jones, 2009; Prince, Thompson, \& Schmuckler, 2009) in order to distinguish the otherwise potentially conflated factors of discriminability and salience.

The present research expands on the concept of dimensional salience in pitch-time integration by manipulating the presence of irrelevant pitch structure in the global temporal task of metrical grouping. Consistent with earlier findings, tonal sequences have the effect of prioritizing the dimension of pitch, even when all other aspects of the stimuli are carefully controlled. Furthermore, this prioritization cannot be attributed to unequal discriminability, or allocation of attention (neither conscious nor inadvertent) to pitch in the context of tonal sequences. These findings, and their implications for the dimensional salience framework, have applications beyond the domain of pitch-time integration in music because all stimuli in our natural environments are multidimensional. The process of integrating these dimensions is common to all perceptual modalities and is thus a crucial component of cognition.

\section{References}

Alain, C., \& Arnott, S. R. (2000). Selectively attending to auditory objects. Frontiers in Bioscience, 5, d202-d212. doi:10.2741/Alain

Atkinson, A. P., Tipples, J., Burt, D. M., \& Young, A. W. (2005). Asymmetric interference between sex and emotion in face perception. Perception \& Psychophysics, 67, 1199-1213. doi:10.3758/BF03193553

Best, V., Ozmeral, E. J., Kopco, N., \& Shinn-Cunningham, B. G. (2008). Object continuity enhances selective auditory attention. PNAS: Proceedings of the National Academy of Sciences of the United States of America, 105, 13174-13178. doi:10.1073/pnas.0803718105

Bharucha, J., \& Krumhansl, C. L. (1983). The representation of harmonic structure in music: Hierarchies of stability as a function of context. Cognition, 13, 63-102. doi:10.1016/0010-0277(83)90003-3

Bigand, E., \& Poulin-Charronnat, B. (2006). Are we "experienced listeners"? A review of the musical capacities that do not depend on formal musical training. Cognition, 100, 100-130. doi:10.1016/j.cognition.2005.11.007

Boltz, M. (1989a). Perceiving the end: Effects of tonal relationships on melodic completion. Journal of Experimental Psychology: Human Perception and Performance, 15, 749-761. doi:10.1037/0096-1523.15.4.749

Boltz, M. (1989b). Rhythm and "good endings": Effects of temporal structure on tonality judgments. Perception \& Psychophysics, 46, 9-17. doi:10.3758/BF03208069

Boltz, M. G. (1992). The remembering of auditory event durations. Journal of Experimental Psychology: Learning, Memory, and Cognition, 18, 938-956. doi:10.1037/0278-7393.18.5.938

Boltz, M. G. (1995). Effects of event structure on retrospective duration judgments. Perception \& Psychophysics, 57, 1080-1096. doi:10.3758/ BF03205466

Boltz, M. G. (1998). The processing of temporal and nontemporal information in the remembering of event durations and musical structure. Journal of Experimental Psychology: Human Perception and Performance, 24, 1087-1104. doi:10.1037/0096-1523.24.4.1087

Boltz, M. G. (1999). The processing of melodic and temporal information: Independent or unified dimensions? Journal of New Music Research, 28 , 67-79. doi:10.1076/jnmr.28.1.67.3121

Brainard, D. H. (1997). The psychophysics toolbox. Spatial Vision, 10, 433-436. doi:10.1163/156856897X00357

Brattico, E., Näätänen, R., \& Tervaniemi, M. (2001). Context effects on pitch perception in musicians and nonmusicians: Evidence from event-relatedpotential recordings. Music Perception, 19, 199-222. doi:10.1525/mp.2001 19.2.199

Brattico, E., Tervaniemi, M., Näätänen, R., \& Peretz, I. (2006). Musical scale properties are automatically processed in the human auditory cortex. Brain Research, 1117, 162-174. doi:10.1016/j.brainres.2006.08 .023

Bregman, A. S. (1990). Auditory scene analysis: The perceptual organization of sound. Cambridge, MA: MIT Press.

Brochard, R., Abecasis, D., Potter, D., Ragot, R., \& Drake, C. (2003). The "ticktock" of our internal clock: Direct brain evidence of subjective accents in isochronous sequences. Psychological Science, 14, 362-366. doi:10.1111/1467-9280.24441 
Brown, S. W., \& Boltz, M. G. (2002). Attentional processes in time perception: Effects of mental workload and event structure. Journal of Experimental Psychology: Human Perception and Performance, 28, 600-615. doi:10.1037/0096-1523.28.3.600

Clarke, E. F., \& Krumhansl, C. L. (1990). Perceiving musical time. Music Perception, 7, 213-252. doi:10.2307/40285462

Cohen, A. J., \& Frankland, B. W. (1990). Scale and serial order information in melodic perception: Independence or interdependence. Canadian Acoustics, 18, 2-20.

Cohen, A. J., Trehub, S. E., \& Thorpe, L. A. (1989). Effects of uncertainty on melodic information-processing. Perception \& Psychophysics, 46, 18-28. doi:10.3758/BF03208070

Cooper, G. W., \& Meyer, L. B. (1960). The rhythmic structure of music. Chicago, IL: University of Chicago Press.

Cousineau, M., Demany, L., \& Pressnitzer, D. (2009). What makes a melody: The perceptual singularity of pitch sequences. Journal of the Acoustical Society of America, 126, 3179-3187. doi:10.1121/1.3257206

Cuddy, L. L., Cohen, A. J., \& Mewhort, D. J. (1981). Perception of structure in short melodic sequences. Journal of Experimental Psychology: Human Perception and Performance, 7, 869-883. doi:10.1037/ 0096-1523.7.4.869

Cuddy, L. L., Cohen, A. J., \& Miller, J. (1979). Melody recognition: The experimental application of musical rules. Canadian Journal of Psychology/ Revue Canadienne De Psychologie, 33, 148-157. doi:10.1037/h0081713

Cumming, R. E. (2010). The interdependence of tonal and durational cues in the perception of rhythmic groups. Phonetica, 67, 219-242. doi:10.1159/ 000324132

Cusack, R., \& Roberts, B. (2000). Effects of differences in timbre on sequential grouping. Perception \& Psychophysics, 62, 1112-1120. doi: 10.3758/BF03212092

Cutting, J. E. (1986). Perception with an eye for motion: Cambridge, MA: MIT Press.

Dawe, L. A., Platt, J. R., \& Racine, R. J. (1993). Harmonic accents in inference of metrical structure and perception of rhythm patterns. Perception \& Psychophysics, 54, 794-807. doi:10.3758/BF03211804

Dawe, L. A., Platt, J. R., \& Racine, R. J. (1994). Inference of metrical structure from perception of iterative pulses within time spans defined by chord changes. Music Perception, 12, 57-76. doi:10.2307/40285755

Dawe, L. A., Platt, J. R., \& Racine, R. J. (1995). Rhythm perception and differences in accent weights for musicians and nonmusicians. Perception \& Psychophysics, 57, 905-914. doi:10.3758/BF03206805

De Freitas, J., Liverence, B. M., \& Scholl, B. J. (2014). Attentional rhythm: A temporal analogue of object-based attention. Journal of Experimental Psychology: General, 143, 71-76.

Deutsch, D. (1999). Grouping mechanisms in music. In D. Deutsch (Ed.), The psychology of music (Vol. 2, pp. 299-348). San Diego, CA: Academic Press. doi:10.1016/B978-012213564-4/50010-X

Deutsch, D., \& Feroe, J. (1981). The internal representation of pitch sequences in tonal music. Psychological Review, 88, 503-522. doi:10.1037/0033295X.88.6.503

Dowling, W. J. (1978). Scale and contour: Two components of a theory of memory for melodies. Psychological Review, 85, 341-354. doi:10.1037/ 0033-295X.85.4.341

Dowling, W. J. (1991). Tonal strength and melody recognition after long and short delays. Perception \& Psychophysics, 50, 305-313. doi:10.3758/ BF03212222

Drake, C., Dowling, W. J., \& Palmer, C. (1991). Accent structures in the reproduction of simple tunes by children and adult pianists. Music Perception, 8, 315-334. doi:10.2307/40285505

Drake, C., \& Palmer, C. (1993). Accent structures in music performance. Music Perception, 10, 343-378. doi:10.2307/40285574

Ellis, R. J., \& Jones, M. R. (2009). The role of accent salience and joint accent structure in meter perception. Journal of Experimental Psychol- ogy: Human Perception and Performance, 35, 264-280. doi:10.1037/ a0013482

Ellis, R. J., \& Jones, M. R. (2010). Rhythmic context modulates foreperiod effects. Attention, Perception, \& Psychophysics, 72, 2274-2288. doi: 10.3758/BF03196701

Everett, W. (2000). Pitch down the middle. In W. Everett (Ed.), Expression in pop-rock music: A collection of critical and analytical essays (pp. 111-174). New York, NY: Garland.

Fedorenko, E., McDermott, J. H., Norman-Haignere, S., \& Kanwisher, N. (2012). Sensitivity to musical structure in the human brain. Journal of Neurophysiology, 108, 3289-3300. doi:10.1152/jn.00209.2012

Fraisse, P. (1982). Rhythm and tempo. In D. Deutsch (Ed.), The psychology of music (pp. 149-180). New York, NY: Academic Press. doi:10.1016/ B978-0-12-213562-0.50010-3

Freedman, E. G. (1999). The role of diatonicism in the abstraction and representation of contour and interval information. Music Perception, 16, 365-387. doi:10.2307/40285797

Garner, W. R. (1974). The processing of information and structure (Vol. 203). Oxford, England: Erlbaum

Garner, W. R. (1976). Interaction of stimulus dimensions in concept and choice processes. Cognitive Psychology, 8, 98-123. doi:10.1016/00100285(76)90006-2

Garner, W. R., \& Felfoldy, G. L. (1970). Integrality of stimulus dimensions in various types of information processing. Cognitive Psychology, 1, 225-241. doi:10.1016/0010-0285(70)90016-2

Geiser, E., Ziegler, E., Jancke, L., \& Meyer, M. (2009). Early electrophysiological correlates of meter and rhythm processing in music perception. Cortex: A Journal Devoted to the Study of the Nervous System and Behavior, 45, 93-102. doi:10.1016/j.cortex.2007.09.010

Goldstone, R. L. (1998). Perceptual learning. Annual Review of Psychology, 49, 585-612. doi:10.1146/annurev.psych.49.1.585

Graham, R., \& LaBar, K. S. (2007). Garner interference reveals dependencies between emotional expression and gaze in face perception Emotion, 7, 296-313. doi:10.1037/1528-3542.7.2.296

Green, K. P., Tomiak, G. R., \& Kuhl, P. K. (1997). The encoding of rate and talker information during phonetic perception. Perception \& Psychophysics, 59, 675-692. doi:10.3758/BF03206015

Grube, M., \& Griffiths, T. D. (2009). Metricality-enhanced temporal encoding and the subjective perception of rhythmic sequences. Cortex: A Journal Devoted to the Study of the Nervous System and Behavior, 45, 72-79. doi:10.1016/j.cortex.2008.01.006

Gürkan Tekman, H. (2002). Perceptual integration of timing and intensity variations in the perception of musical accents. Journal of General Psychology, 129, 181-191. doi:10.1080/00221300209603137

Handel, S. (1995). Timbre perception and auditory object identification. In B. C. J. Moore (Ed.), Hearing: Handbook of perception and cognition (2nd ed., pp. 425-461). San Diego, CA: Academic Press.

Handel, S., \& Lawson, G. R. (1983). The contextual nature of rhythmic interpretation. Perception \& Psychophysics, 34, 103-120. doi:10.3758/ BF03211335

Hannon, E. E., \& Johnson, S. P. (2005). Infants use meter to categorize rhythms and melodies: Implications for musical structure learning. Cog nitive Psychology, 50, 354-377. doi:10.1016/j.cogpsych.2004.09.003

Hannon, E. E., Snyder, J. S., Eerola, T., \& Krumhansl, C. L. (2004). The role of melodic and temporal cues in perceiving musical meter. Journal of Experimental Psychology: Human Perception and Performance, 30 956-974. doi:10.1037/0096-1523.30.5.956

Haxby, J. V., Hoffman, E. A., \& Gobbini, M. I. (2000). The distributed human neural system for face perception. Trends in Cognitive Sciences, 4, 223-233. doi:10.1016/S1364-6613(00)01482-0

Hay, J. S. F., \& Diehl, R. L. (2007). Perception of rhythmic grouping Testing the iambic/trochaic law. Perception \& Psychophysics, 69, 113122. doi:10.3758/BF03194458 
Hébert, S., \& Cuddy, L. L. (2002). Detection of metric structure in auditory figural patterns. Perception \& Psychophysics, 64, 909-918. doi:10.3758/ BF03196795

Hébert, S., \& Peretz, I. (1997). Recognition of music in long-term memory: Are melodic and temporal patterns equal partners? Memory \& Cognition, 25, 518-533. doi:10.3758/BF03201127

Hermens, F., Scharnowski, F., \& Herzog, M. H. (2010). Automatic grouping of regular structures. Journal of Vision, 10, 5. doi:10.1167/10.8.5

Huron, D., \& Royal, M. (1996). What is melodic accent? Converging evidence from musical practice. Music Perception, 13, 489-516. doi:10.2307/ 40285700

Iversen, J. R., Patel, A. D., \& Ohgushi, K. (2008). Perception of rhythmic grouping depends on auditory experience. Journal of the Acoustical Society of America, 124, 2263-2271. doi:10.1121/1.2973189

Iversen, J. R., Repp, B. H., \& Patel, A. D. (2009). Top-down control of rhythm perception modulates early auditory responses. In S. Dalla Bella, N. Kraus, K. Overy, C. Pantev, J. S. Snyder, M. Tervaniemi, . . . G. Schlaug (Eds.), Neurosciences and music III: Disorders and plasticity (Vol. 1169, pp. 58-73). Oxford, England: Blackwell Publishing.

Janata, P., Birk, J. L., Van Horn, J. D., Leman, M., Tillmann, B., \& Bharucha, J. J. (2002). The cortical topography of tonal structures underlying Western music. Science, 298, 2167-2170. doi:10.1126/ science. 1076262

Jones, M. R. (1976). Levels of structure in reconstruction of temporal and spatial serial patterns. Journal of Experimental Psychology: Human Learning and Memory, 2, 475-488. doi:10.1037/0278-7393.2.4.475

Jones, M. R. (1987). Dynamic pattern structure in music-Recent theory and research. Perception \& Psychophysics, 41, 621-634. doi:10.3758/ BF03210494

Jones, M. R., \& Boltz, M. G. (1989). Dynamic attending and responses to time. Psychological Review, 96, 459-491. doi:10.1037/0033-295X.96 .3 .459

Jones, M. R., Boltz, M. G., \& Kidd, G. (1982). Controlled attending as a function of melodic and temporal context. Perception \& Psychophysics, 32, 211-218. doi:10.3758/BF03206225

Jones, M. R., Boltz, M. G., \& Klein, J. M. (1993). Expected endings and judged duration. Memory \& Cognition, 21, 646-665. doi:10.3758/ BF03197196

Jones, M. R., \& Pfordresher, P. Q. (1997). Tracking musical patterns using joint accent structure. Canadian Journal of Experimental Psychology/Revue Canadienne de Psychologie Expérimentale, 51, 271-291. doi:10.1037/ 1196-1961.51.4.271

Jones, M. R., \& Ralston, J. T. (1991). Some influences of accent structure on melody recognition. Memory \& Cognition, 19, 8-20. doi:10.3758/ BF03198492

Karnadewi, F., \& Lipp, O. V. (2011). The processing of invariant and variant face cues in the garner paradigm. Emotion, 11, 563-571. doi: $10.1037 / \mathrm{a} 0021333$

Keller, P. E., \& Burnham, D. K. (2005). Musical meter in attention to multipart rhythm. Music Perception, 22, 629-661. doi:10.1525/mp .2005.22.4.629

Keller, P. E., \& Repp, B. H. (2005). Staying offbeat: Sensorimotor syncopation with structured and unstructured auditory sequences. Psychological Research, 69, 292-309. doi:10.1007/s00426-004-0182-9

Kimchi, R. (2009). Perceptual organization and visual attention (Vol. 176, pp. 15-33). Amsterdam, The Netherland: Elsevier Science.

Kimchi, R., Yeshurun, Y., \& Cohen-Savransky, A. (2007). Automatic, stimulus-driven attentional capture by objecthood. Psychonomic Bulletin \& Review, 14, 166-172. doi:10.3758/BF03194045

Koelsch, S. (2005). Neural substrates of processing syntax and semantics in music. Current Opinion in Neurobiology, 15, 207-212. doi:10.1016/ j.conb.2005.03.005
Koelsch, S., Schröger, E., \& Gunter, T. C. (2002). Music matters: Preattentive musicality of the human brain. Psychophysiology, 39, 38-48. doi:10.1111/1469-8986.3910038

Krumhansl, C. L. (1990). Cognitive foundations of musical pitch. New York, NY: Oxford University Press.

Krumhansl, C. L. (2000). Rhythm and pitch in music cognition. Psychological Bulletin, 126, 159-179. doi:10.1037/0033-2909.126.1.159

Krumhansl, C. L., Bharucha, J. J., \& Kessler, E. J. (1982). Perceived harmonic structure of chords in three related musical keys. Journal of Experimental Psychology: Human Perception and Performance, 8, 2436. doi:10.1037/0096-1523.8.1.24

Krumhansl, C. L., \& Cuddy, L. L. (2010). A theory of tonal hierarchies in music. In M. R. Jones, R. R. Fay, \& A. N. Popper (Eds.), Music perception. Springer handbook of auditory research (Vol. 36, pp. 5187). New York, NY: Springer Science.

Krumhansl, C. L., \& Iverson, P. (1992). Perceptual interactions between musical pitch and timbre. Journal of Experimental Psychology: Human Perception and Performance, 18, 739-751. doi:10.1037/0096-1523.18 .3 .739

Krumhansl, C. L., \& Schmuckler, M. A. (1986, July). Key-finding in music: An algorithm based on pattern matching to tonal hierarchies. Paper presented at the 19th Annual Meeting of the Society of Mathematical Psychology, Cambridge, MA.

Kubovy, M., \& Van Valkenburg, D. (2001). Auditory and visual objects. Cognition, 80, 97-126. doi:10.1016/S0010-0277(00)00155-4

Ladinig, O., Honing, H., Haden, G., \& Winkler, I. (2009). Probing attentive and preattentive emergent meter in adult listeners without extensive music training. Music Perception, 26, 377-386. doi:10.1525/mp.2009 .26.4.377

Lerdahl, F., \& Jackendoff, R. (1983). A generative theory of tonal music. Cambridge, MA: MIT Press.

London, J. (1995). Some examples of complex meters and their implications for models of metric perception. Music Perception, 13, 59-77. doi: $10.2307 / 40285685$

London, J. (2004). Hearing in time: Psychological aspects of musical meter. New York, NY: Oxford University Press. doi:10.1093/acprof: oso/9780195160819.001.0001

London, J., Himberg, T., \& Cross, I. (2009). The effect of structural and performance factors in the perception of anacruses. Music Perception, 27, 103-120. doi:10.1525/mp.2009.27.2.103

Loui, P., Grent-'t-Jong, T., Torpey, D., \& Woldorff, M. (2005). Effects of attention on the neural processing of harmonic syntax in Western music. Cognitive Brain Research, 25, 678-687. doi:10.1016/j.cogbrainres.2005 .08 .019

Marks, L. E., \& Gescheider, G. A. (2002). Psychophysical scaling. Hoboken, NJ: Wiley.

Marmel, F., Perrin, F., \& Tillmann, B. (2011). Tonal expectations influence early pitch processing. Journal of Cognitive Neuroscience, 23, 30953104. doi:10.1162/jocn.2011.21632

Marmel, F., Tillmann, B., \& Dowling, W. J. (2008). Tonal expectations influence pitch perception. Perception \& Psychophysics, 70, 841-852. doi:10.3758/PP.70.5.841

Massaro, D. W. (1989). Testing between the trace model and the fuzzy logical model of speech-perception. Cognitive Psychology, 21, 398421. doi:10.1016/0010-0285(89)90014-5

Massaro, D. W., \& Friedman, D. (1990). Models of integration given multiple sources of information. Psychological Review, 97, 225-252. doi:10.1037/0033-295X.97.2.225

MathWorks. (2004). Matlab [Computer software]. Natick, MA: The MathWorks.

McAuley, J. D., \& Semple, P. (1999). The effect of tempo and musical experience on perceived beat. Australian Journal of Psychology, 51, 176-187. doi:10.1080/00049539908255355 
McClelland, J. L., \& Elman, J. L. (1986). The trace model of speech perception. Cognitive Psychology, 18, 1-86. doi:10.1016/0010-0285(86)90015-0

Melara, R. D., \& Mounts, J. R. W. (1993). Selective attention to Stroop dimensions: Effects of baseline discriminability, response mode, and practice. Memory \& Cognition, 21, 627-645. doi:10.3758/BF03197195

Melara, R. D., \& Mounts, J. R. W. (1994). Contextual influences on interactive processing: Effects of discriminability, quantity, and uncertainty. Perception \& Psychophysics, 56, 73-90. doi:10.3758/BF03211692

Monahan, C. B. (1993). Parallels between pitch and time and how they go together. In T. J. Tighe \& W. J. Dowling (Eds.), Psychology and music: The understanding of melody and rhythm (pp. 121-154). Hillsdale, NJ: Erlbaum.

Monahan, C. B., \& Carterette, E. C. (1985). Pitch and duration as determinants of musical space. Music Perception, 3, 1-32. doi:10.2307/40285320

Monahan, C. B., Kendall, R. A., \& Carterette, E. C. (1987). The effect of melodic and temporal contour on recognition memory for pitch change. Perception \& Psychophysics, 41, 576-600. doi:10.3758/BF03210491

Mullennix, J. W., \& Pisoni, D. B. (1990). Stimulus variability and processing dependencies in speech-perception. Perception \& Psychophysics, 47, 379-390. doi:10.3758/BF03210878

Nittono, H., Bito, T., Hayashi, M., Sakata, S., \& Hori, T. (2000). Event-related potentials elicited by wrong terminal notes: Effects of temporal disruption. Biological Psychology, 52, 1-16. doi:10.1016/S0301-0511(99)00042-3

Nosofsky, R. M. (1986). Attention, similarity, and the identificationcategorization relationship. Journal of Experimental Psychology: General, 115, 39-61. doi:10.1037/0096-3445.115.1.39

Oden, G. C., \& Massaro, D. W. (1978). Integration of featural information in speech perception. Psychological Review, 85, 172-191. doi:10.1037/ 0033-295X.85.3.172

Palmer, C., \& Krumhansl, C. L. (1987a). Independent temporal and pitch structures in determination of musical phrases. Journal of Experimental Psychology: Human Perception and Performance, 13, 116-126. doi: 10.1037/0096-1523.13.1.116

Palmer, C., \& Krumhansl, C. L. (1987b). Pitch and temporal contributions to musical phrase perception - effects of harmony, performance timing, and familiarity. Perception \& Psychophysics, 41, 505-518. doi:10.3758/ BF03210485

Palmer, C., \& Krumhansl, C. L. (1990). Mental representations for musical meter. Journal of Experimental Psychology: Human Perception and Performance, 16, 728-741. doi:10.1037/0096-1523.16.4.728

Parncutt, R. (1994). A perceptual model of pulse salience and metrical accent in musical rhythms. Music Perception, 11, 409-464. doi:10.2307/ 40285633

Parton, A., Donnelly, N., \& Usher, M. (2001). The effects of temporal synchrony on the perceived organization of elements in spatially symmetric and asymmetric grids. Visual Cognition, 8, 637-654. doi:10.1080/ 13506280143000179

Patel, A. D., Iversen, J. R., Chen, Y. Q., \& Repp, B. H. (2005). The influence of metricality and modality on synchronization with a beat. Experimental Brain Research, 163, 226-238. doi:10.1007/s00221-0042159-8

Pfordresher, P. Q. (2003). The role of melodic and rhythmic accents in musical structure. Music Perception, 20, 431-464. doi:10.1525/mp.2003 .20 .4 .431

Potter, D. D., Fenwick, M., Abecasis, D., \& Brochard, R. (2009). Perceiving rhythm where none exists: Event-related potential (ERP) correlates of subjective accenting. Cortex: A Journal Devoted to the Study of the Nervous System and Behavior, 45, 103-109. doi:10.1016/j.cortex.2008 .01 .004

Povel, D. J., \& Essens, P. (1985). Perception of temporal patterns. Music Perception, 2, 411-440. doi:10.2307/40285311

Pressing, J. (1983). Cognitive isomorphisms in world music: West Africa, the Balkans, Thailand and Western tonality. Studies in Music, 17, $38-61$.
Preusser, D., Garner, W. R., \& Gottwald, R. L. (1970). Perceptual organization of 2-element temporal patterns as a function of their component one-element patterns. The American Journal of Psychology, 83, 151170. doi: $10.2307 / 1421321$

Prince, J. B. (2011). The integration of stimulus dimensions in the perception of music. The Quarterly Journal of Experimental Psychology, 64, 2125-2152. doi:10.1080/17470218.2011.573080

Prince, J. B., \& Pfordresher, P. Q. (2012). The role of pitch and temporal diversity in the perception and production of musical sequences. Acta Psychologica, 141, 184-198. doi:10.1016/j.actpsy.2012.07.013

Prince, J. B., Schmuckler, M. A., \& Thompson, W. F. (2009). The effect of task and pitch structure on pitch-time interactions in music. Memory \& Cognition, 37, 368-381. doi:10.3758/MC.37.3.368

Prince, J. B., Thompson, W. F., \& Schmuckler, M. A. (2009). Pitch and time, tonality and meter: How do musical dimensions combine? Journal of Experimental Psychology: Human Perception and Performance, 35, 1598-1617. doi:10.1037/a0016456

Repp, B. H. (1992). Probing the cognitive representation of musical time structural constraints on the perception of timing perturbations. Cognition, 44, 241-281. doi:10.1016/0010-0277(92)90003-Z

Repp, B. H. (1995). Detectability of duration and intensity increments in melody tones: A partial connection between music perception and performance. Perception \& Psychophysics, 57, 1217-1232. doi:10.3758/ BF03208378

Repp, B. H. (2005). Sensorimotor synchronization: A review of the tapping literature. Psychonomic Bulletin \& Review, 12, 969-992. doi:10.3758/ BF03206433

Repp, B. H. (2007). Hearing a melody in different ways: Multistability of metrical interpretation, reflected in rate limits of sensorimotor synchronization. Cognition, 102, 434-454. doi:10.1016/j.cognition.2006.02.003

Repp, B. H. (2010). Do metrical accents create illusory phenomenal accents? Attention Perception, \& Psychophysics, 72, 1390-1403. doi: 10.3758/APP.72.5.1390

Repp, B. H., Iversen, J. R., \& Patel, A. D. (2008). Tracking an imposed beat within a metrical grid. Music Perception, 26, 1-18. doi:10.1525/ mp.2008.26.1.1

Repp, B. H., \& Su, Y. H. (2013). Sensorimotor synchronization: A review of recent research (2006-2012). Psychonomic Bulletin \& Review, 20 , 403-452. doi:10.3758/s13423-012-0371-2

Russell, C., \& Driver, J. (2005). New indirect measures of "inattentive" visual grouping in a change-detection task. Perception \& Psychophysics, 67, 606-623. doi:10.3758/BF03193518

Sarrazin, J.-C., Giraudo, M.-D., \& Pittenger, J. B. (2007). Tau and Kappa effects in physical space: The case of audition. Psychological Research, 71, 201-218. doi:10.1007/s00426-005-0019-1

Schellenberg, E. G., Krysciak, A. M., \& Campbell, R. J. (2000). Perceiving emotion in melody: Interactive effects of pitch and rhythm. Music Perception, 18, 155-171. doi:10.2307/40285907

Schellenberg, E. G., Stalinski, S. M., \& Marks, B. M. (2014). Memory for surface features of unfamiliar melodies: Independent effects of changes in pitch and tempo. Psychological Research, 78, 84-95. doi:10.1007/ s00426-013-0483-y

Schenker, H. (1979). Free composition [Der freie Satz] (E. Ostler, Trans.) New York, NY: Longman. (Original work published 1935)

Schmuckler, M. A. (2009). Components of melodic processing. In S. Hallam, I. Cross, \& M. Thaut (Eds.), Oxford handbook of music psychology (pp. 93-106). New York, NY: Oxford University Press.

Schultz, B. G., Stevens, C. J., Keller, P. E., \& Tillmann, B. (2013). The implicit learning of metrical and nonmetrical temporal patterns. Quarterly Journal of Experimental Psychology, 66, 360-380. doi:10.1080/ 17470218.2012 .712146

Schulze, K., Dowling, W. J., \& Tillmann, B. (2012). Working memory for tonal and atonal sequences during a forward and a backward recognition task. Music Perception, 29, 255-267. doi:10.1525/mp.2012.29.3.255 
Sloboda, J. A., \& Gregory, A. H. (1980). The psychological reality of musical segments. Canadian Journal of Psychology/Revue Canadienne de Psychologie, 34, 274-280. doi:10.1037/h0081052

Smith, K. C., \& Cuddy, L. L. (1989). Effects of metric and harmonic rhythm on the detection of pitch alterations in melodic sequences. Journal of Experimental Psychology: Human Perception and Performance, 15, 457-471. doi:10.1037/0096-1523.15.3.457

Snyder, J. S., \& Alain, C. (2007). Toward a neurophysiological theory of auditory stream segregation. Psychological Bulletin, 133, 780-799. doi: 10.1037/0033-2909.133.5.780

Snyder, J. S., Gregg, M. K., Weintraub, D. M., \& Alain, C. (2012). Attention, awareness, and the perception of auditory scenes. Frontiers in Psychology, 3. doi:10.3389/fpsyg.2012.00015

Snyder, J. S., \& Krumhansl, C. L. (2001). Tapping to ragtime: Cues to pulse finding. Music Perception, 18, 455-489. doi:10.1525/mp.2001.18 .4 .455

Snyder, J. S., \& Large, E. W. (2005). Gamma-band activity reflects the metric structure of rhythmic tone sequences. Cognitive Brain Research, 24, 117-126. doi:10.1016/j.cogbrainres.2004.12.014

Stevens, J. C., \& Marks, L. E. (1980). Cross-modality matching functions generated by magnitude estimation. Perception \& Psychophysics, 27, 379-389. doi:10.3758/BF03204456

Strother, L., \& Kubovy, M. (2012). Structural salience and the nonaccidentality of a Gestalt. Journal of Experimental Psychology: Human Perception and Performance, 38, 827-832. doi:10.1037/a0027939

Thomassen, J. M. (1982). Melodic accent: Experiments and a tentative model. Journal of the Acoustical Society of America, 71, 1596-1605. doi:10.1121/1.387814

Tillmann, B., Janata, P., Birk, J. L., \& Bharucha, J. J. (2003). The costs and benefits of tonal centers for chord processing. Journal of Experimental Psychology: Human Perception and Performance, 29, 470-482. doi: 10.1037/0096-1523.29.2.470

Tillmann, B., Janata, P., Birk, J. L., \& Bharucha, J. J. (2008). Tonal centers and expectancy: Facilitation or inhibition of chords at the top of the harmonic hierarchy? Journal of Experimental Psychology: Human Perception and Performance, 34, 1031-1043. doi:10.1037/0096-1523.34.4 1031

Tillmann, B., \& Lebrun-Guillaud, G. (2006). Influence of tonal and temporal expectations on chord processing and on completion judgments of chord sequences. Psychological Research, 70, 345-358. doi:10.1007/ s00426-005-0222-0

Tillmann, B., Stevens, C., \& Keller, P. E. (2011). Learning of timing patterns and the development of temporal expectations. Psychological Research, 75, 243-258. doi:10.1007/s00426-010-0302-7

Tong, Y. X., Francis, A. L., \& Gandour, J. T. (2008). Processing dependencies between segmental and suprasegmental features in Mandarin
Chinese. Language and Cognitive Processes, 23, 689-708. doi:10.1080/ 01690960701728261

Trainor, L. J., \& Corrigall, K. A. (2010). Music acquisition and effects of musical experience. In M. R. Jones, R. R. Fay, \& A. N. Popper (Eds.), Springer handbook of auditory research: Music perception (pp. 89127): New York, NY: Springer

Trainor, L. J., \& Trehub, S. E. (1992). A comparison of infants and adults sensitivity to Western musical structure. Journal of Experimental Psychology: Human Perception and Performance, 18, 394-402. doi:10.1037/00961523.18.2.394

Trainor, L. J., \& Trehub, S. E. (1993). What mediates infants and adults superior processing of the major over the augmented triad. Music Perception, 11, 185-196. doi:10.2307/40285615

Trainor, L. J., \& Trehub, S. E. (1994). Key membership and implied harmony in Western tonal music: Developmental perspectives. Perception \& Psychophysics, 56, 125-132. doi:10.3758/BF03213891

van Noorden, L. (1975). Temporal coherence in the perception of tone sequences (Doctoral dissertation). Technical University Eindhoven, Eindhoven, The Netherlands.

Vos, P. G. (1977). Temporal duration factors in perception of auditory rhythmic patterns. Scientific Aesthetics/Sciences de L'Art, 1, 183-199.

Wagemans, J., Elder, J. H., Kubovy, M., Palmer, S. E., Peterson, M. A., Singh, M., \& von der Heydt, R. (2012). A century of Gestalt psychology in visual perception: I. Perceptual grouping and figure-ground organization. Psychological Bulletin, 138, 1172-1217. doi:10.1037/a0029333

Warrier, C. M., \& Zatorre, R. (2002). Influence of tonal context and timbral variation on perception of pitch. Perception \& Psychophysics, 64, 198 207. doi:10.3758/BF03195786

Winkler, I., Denham, S. L., \& Nelken, I. (2009). Modeling the auditory scene Predictive regularity representations and perceptual objects. Trends in Cognitive Sciences, 13, 532-540. doi:10.1016/j.tics.2009.09.003

Yoshida, K. A., Iversen, J. R., Patel, A. D., Mazuka, R., Nito, H., Gervain, J., \& Werker, J. F. (2010). The development of perceptual grouping biases in infancy: A Japanese-English cross-linguistic study. Cognition, 115, 356-361. doi:10.1016/j.cognition.2010.01.005

Zentner, M., \& Eerola, T. (2010). Rhythmic engagement with music in infancy. PNAS: Proceedings of the National Academy of Sciences of the United States of America, 107, 5768-5773. doi:10.1073/pnas 1000121107

Zhao, M., \& Hayward, W. G. (2013). Integrative processing of invariant aspects of faces: Effect of gender and race processing on identity analysis. Journal of Vision, 13, 15. doi:10.1167/13.1.15

Received January 10, 2014

Revision received July 14, 2014 Accepted July 18, 2014 